ARTICLE

https://doi.org/10.1038/s41467-021-25633-0

OPEN

\title{
Structural determinants and regulation of spontaneous activity in $\mathrm{GABA}_{\mathrm{A}}$ receptors
}

\author{
Craig A. Sexton (1) 1, Reka Penzinger (1) 1, Martin Mortensen", Damian P. Bright ${ }^{1} \&$ Trevor G. Smart (i) $^{1 凶}$
}

$G A B A_{A}$ receptors are vital for controlling neuronal excitability and can display significant levels of constitutive activity that contributes to tonic inhibition. However, the mechanisms underlying spontaneity are poorly understood. Here we demonstrate a strict requirement for $\beta 3$ subunit incorporation into receptors for spontaneous gating, facilitated by $\alpha 4, \alpha 6$ and $\delta$ subunits. The crucial molecular determinant involves four amino acids (GKER) in the $\beta 3$ subunit's extracellular domain, which interacts with adjacent receptor subunits to promote transition to activated, open channel conformations. Spontaneous activity is further regulated by $\beta 3$ subunit phosphorylation and by allosteric modulators including neurosteroids and benzodiazepines. Promoting spontaneous activity reduced neuronal excitability, indicating that spontaneous currents will alter neural network activity. This study demonstrates how regional diversity in $\mathrm{GABA}_{A}$ receptor isoform, protein kinase activity, and neurosteroid levels, can impact on tonic inhibition through the modulation of spontaneous $G_{A B A}$ receptor gating.

${ }^{1}$ Department of Neuroscience, Physiology \& Pharmacology, UCL, London, UK. ®email: t.smart@ucl.ac.uk 
nhibition in the brain is predominantly provided by the neurotransmitter $\gamma$-aminobutyric acid (GABA) activating $\mathrm{GABA}_{\mathrm{A}}$ receptors $\left(\mathrm{GABA}_{\mathrm{A}} \mathrm{Rs}\right)$. These heteropentameric receptors are formed from an array of subunits $(\alpha 1-6, \beta 1-3, \gamma 1-3$, $\delta, \varepsilon, \pi, \theta$ and $\rho 1-3)$, producing receptors with diverse functional and pharmacological properties ${ }^{1,2}$. Despite the potential for significant diversity, limited isoforms are expressed in vivo due to the preferential assembly of subunits ${ }^{3}$. The most common subunit configuration consists of two $\alpha$, two $\beta$ and a single $\gamma$ or $\delta$ subunit in a clockwise $\alpha-\beta-\alpha-\beta-\gamma / \delta$ arrangement, when viewed extracellularly ${ }^{4,5}$. Synaptic receptors typically comprise $\alpha 1-3, \beta$ and $\gamma$ subunits, while extrasynaptic receptors contain $\alpha 4 / 6, \beta$ and $\delta$ subunits $^{6}$. Receptors composed of $\alpha 5, \beta$ and $\gamma$ subunits localise to both synaptic and extrasynaptic areas ${ }^{7,8}$.

Extrasynaptic receptors typically exhibit higher sensitivities to GABA and less desensitisation than their synaptic counterparts, permitting mediation of tonic inhibition through persistent activation by ambient $\mathrm{GABA}^{6,9,10}$. Previous studies in hippocampal neurons have also reported a GABA-independent, $\mathrm{GABA}_{\mathrm{A}} \mathrm{R}$-mediated, component to the tonic current ${ }^{11-13}$. This accords with previous demonstrations of spontaneity in recombinant $\mathrm{GABA}_{\mathrm{A}} \mathrm{R}$ isoforms, including: $\beta 1 / 3$ homomers ${ }^{14,15}$, $\alpha 1 \beta 1$ diheteromers ${ }^{16}, \varepsilon$-containing receptors ${ }^{17}$ and the more widely expressed $\alpha 1 \beta 1 \gamma 2$ and $\alpha 4 \beta 3 \delta$ receptors ${ }^{16,18}$. This spontaneous activity is manifest at the single-channel level by brief, infrequent openings in the absence of agonist, resulting in a persistent holding current that contributes towards tonic inhibition ${ }^{13,18-20}$. The effects of tonic inhibition on neuronal excitability have been extensively studied. In addition to membrane hyperpolarisation produced by $\mathrm{GABA}_{\mathrm{A}} \mathrm{R}$ activation in most mature neurons, continuously active receptors reduce membrane resistance, decreasing both the magnitude, duration and length of travel for membrane voltage changes occurring in response to transmembrane ionic current ${ }^{21,22}$. This shunting inhibition modulates the propagation and integration of excitatory inputs, controlling neuronal input-output relationships ${ }^{21,23}$. By contributing to tonic inhibition, spontaneously active $\mathrm{GABA}_{\mathrm{A}}$ Rs are predicted to have important consequences for neuronal computation and network activity ${ }^{13}$.

In this study we have identified $\mathrm{GABA}_{\mathrm{A}} \mathrm{R}$ isoforms that display a propensity for spontaneous gating. Notably, the $\beta 3$ subunit is essential for enabling heteromers to gate spontaneously, and this depends on key residues within the extracellular domain that can interact with adjacent subunits to stabilise an agonistindependent open channel conformation. These spontaneous currents are regulated by endogenous modulators, such as protein kinases and neurosteroids, and by other ligands. Our results reveal that modulation of spontaneous currents regulates neuronal excitability, representing an important physiological mechanism through which tonic inhibition can be dynamically controlled.

\section{Results}

$\beta 3$ subunits are required for $\mathrm{GABA}_{\mathrm{A}} \mathrm{Rs}$ to spontaneously gate. Common isoforms of the $\mathrm{GABA}_{\mathrm{A}} \mathrm{R}$ were initially screened for spontaneous activity by recording from HEK cells expressing discrete synaptic- $(\alpha 1 \beta 2 / 3 \gamma 2 \mathrm{~L})$ and extrasynaptic-type receptors $(\alpha 4 / 6 \beta 2 / 3 \delta)$, and those capable of expression in both domains $(\alpha 5 \beta 2 / 3 \gamma 2 L)$. Spontaneous activity was quantified for each receptor subtype by sequentially applying saturating concentrations of GABA $(500 \mu \mathrm{M})$ and picrotoxin $(\mathrm{PTX}, 100 \mu \mathrm{M})$ to determine the maximum agonist-activated $\left(\mathrm{I}_{\mathrm{Max}}\right)$ and picrotoxinsensitive $\left(\mathrm{I}_{\mathrm{PTX}}\right)$ currents, respectively (Fig. 1a). PTX is a usedependent allosteric antagonist at $\mathrm{GABA}_{\mathrm{A}} \mathrm{Rs}$ and will inhibit constitutively active receptors. The $\mathrm{I}_{\mathrm{PTX}}$ was then normalised (\%) to the total GABA ${ }_{\mathrm{A}} \mathrm{R}$ current $\left(\mathrm{I}_{\mathrm{Max}}+\mathrm{I}_{\mathrm{PTX}}\right)$ to estimate the level of spontaneous current ( $\mathrm{I}_{\text {spont }}$ ). The data indicated that only receptors containing the $\beta 3$ subunit displayed a spontaneous current. Exchanging $\beta 3$ for $\beta 2$ eliminated spontaneous gating, independent of the identity of co-assembled $\alpha, \gamma 2$ and $\delta$ subunits (Fig. 1b; Supplementary Fig. 1a; Supplementary Table 1). Spontaneous activity was also absent for receptors containing the $\beta 1$ subunit co-assembled with $\alpha 4$ and $\delta$ (Fig. 1c; Supplementary Table 1).

Other subunits do affect spontaneity, notably $\delta$-containing receptors support significantly higher levels of spontaneous current than $\gamma$-containing counterparts (Supplementary Fig. 1a). However, comparing normalised $\mathrm{I}_{\text {spont }}$ between these receptor subtypes is potentially confounded by the partial agonist behaviour of GABA at $\delta$-containing receptors ${ }^{24}$. To account for this, we used the $\mathrm{GABA}_{\mathrm{A}} \mathrm{R}$ agonist THIP (4,5,6,7-tetrahydroisoxazolo[5,4-c]pyridin-3-ol) to maximally activate $\delta$-containing receptors $^{24}$. As expected, $\mathrm{I}_{\mathrm{Max}}$ for $\alpha 4 \beta 3 \delta$ receptors was larger when using THIP $(3 \mathrm{mM})$ compared to GABA, resulting in a small reduction of $I_{\text {spont }}$ (Fig. 1d). Nevertheless, $\alpha 4 \beta 3 \delta$ receptors still exhibited significantly larger $I_{\text {spont }}$ than $\alpha 1 \beta 3 \gamma 2 \mathrm{~L}$ receptors when normalised using maximal currents evoked by full agonists. Therefore, even accounting for differences in agonist efficacies, spontaneous activity of extrasynaptic-type receptors is greater than for synaptic-type isoforms. Given that these extrasynaptic $\delta$ $\mathrm{GABA}_{\mathrm{A}} \mathrm{Rs}(\alpha 4 \beta 3 \delta$ and $\alpha 6 \beta 3 \delta)$ are important for generating tonic current in various brain regions ${ }^{22}$, this suggests that tonic inhibition in the brain may represent a combination of GABAdependent and -independent receptor activity.

Cells transfected with the three subunit cDNAs, $\alpha 4, \beta 3$ and $\delta$, could theoretically also express sub-populations of homomeric $\beta 3$ and diheteromeric $\alpha 4 \beta 3 \mathrm{GABA}_{\mathrm{A}} \mathrm{Rs}$, along with triheteromeric $\alpha 4 \beta 3 \delta$ receptors. To assess whether these two sub-populations contributed to the spontaneous current, especially given that homomeric $\beta 3$ receptors are constitutively active ${ }^{14}$, we measured spontaneous currents generated by $\beta 3$ and $\alpha 4 \beta 3$ receptors expressed separately to determine if these assemblies represent significant populations in cells expressing $\alpha 4 \beta 3 \delta$ receptors.

Transfection with all three ( $\alpha 4, \beta 3$ and $\delta)$, two ( $\alpha 4$ and $\beta 3$ ) or just a single $(\beta 3) \mathrm{cDNA}$ showed that only cells expressing all three subunits exhibited significant spontaneous currents (Fig. 1e, Supplementary Fig. 1b). Hence, even under conditions ideal for the assembly of $\alpha 4 \beta 3$ diheteromers and $\beta 3$ homomers, these receptors showed little spontaneous activity, despite appreciable levels of expression ( $\alpha 4 \beta 3$ : $237 \pm 95 \mathrm{pA}$ activated by $500 \mu \mathrm{M}$ GABA, $n=7 ; \beta 3: 220 \pm 94$ pA evoked by $100 \mu \mathrm{M}$ pentobarbital, $n=11)$. Pharmacological tools were also employed to assess the relative expression of these receptor sub-populations in $\alpha 4 \beta 3 \delta$ transfected cells. The competitive $\mathrm{GABA}_{\mathrm{A}} \mathrm{R}$ antagonist gabazine $(1 \mu \mathrm{M})$ behaved as an inverse agonist for cells expressing $\alpha 4, \beta 3$ and $\delta$ receptors, but not with $\beta 3$ alone (Fig. 1f), suggesting most receptors possessed an orthosteric binding site (e.g. $\alpha 4 \beta 3, \alpha 4 \beta 3 \delta$ ) contrasting with $\beta 3$ homomers. To discriminate between $\alpha 4 \beta 3$ and $\alpha 4 \beta 3 \delta$ receptors, we used $\mathrm{Zn}^{2+}$, which inhibits diheteromeric $\alpha \beta$ receptors with significantly higher potency $(\mathrm{nM})$ compared to triheteromeric $\alpha \beta \delta$ receptors $(\mu \mathrm{M})^{25}$. Application of $10 \mathrm{nM} \mathrm{Zn}{ }^{2+}$ significantly inhibited responses to $30 \mu \mathrm{M}$ GABA by $\sim 80 \%$ for cells expressing $\alpha 4 \beta 3$ subunits, with little effect on GABA currents recorded from $\alpha 4 \beta 3 \delta$ - or $\alpha 4 \beta 3 \gamma 2 \mathrm{~L}$-expressing cells (Supplementary Fig. 2a), suggesting minimal expression of $\alpha 4 \beta 3$ receptors when either $\delta$ or $\gamma 2 \mathrm{~L}$ is included in the transfection. We confirmed the incorporation of the $\delta$ subunit into receptors using the selective potentiator DS2 $26(5 \mu \mathrm{M})$, which potentiated $0.3 \mu \mathrm{M}$ GABA responses from $\alpha 4 \beta 3 \delta$, but not $\alpha 4 \beta 3$-expressing, cells (Supplementary Fig. 2b). Together, these data indicate that when the three subunit cDNAs $\alpha 4, \beta 3$ and $\delta$ are co-transfected, the 
a

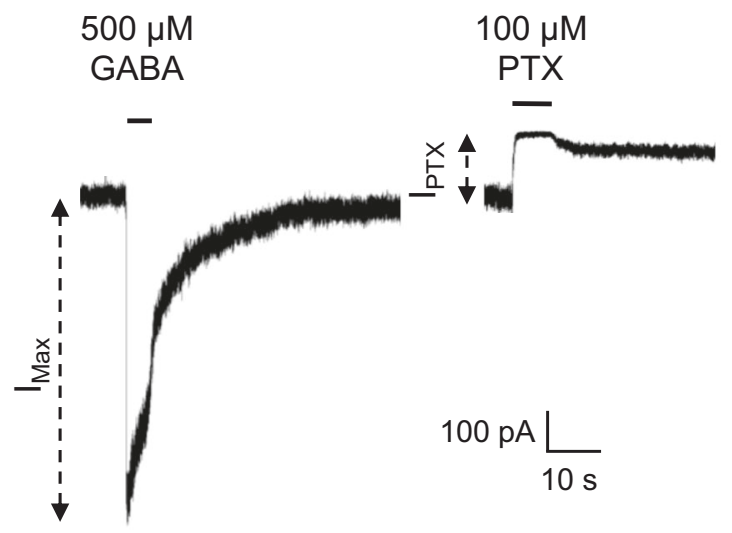

C
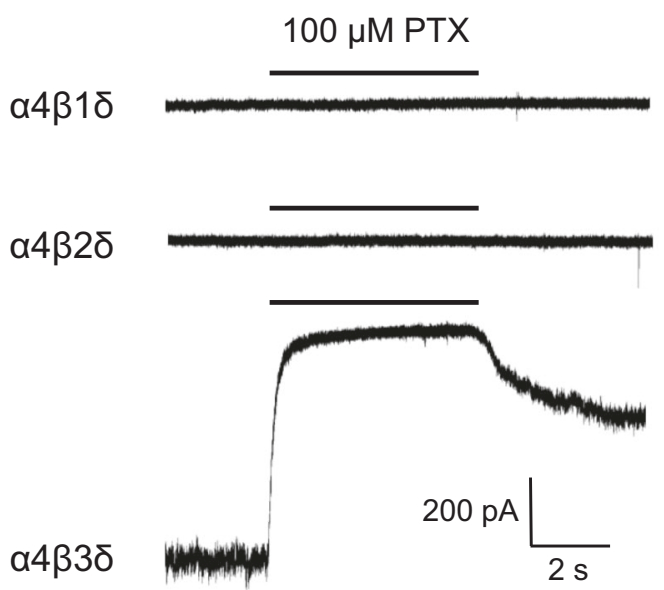

e

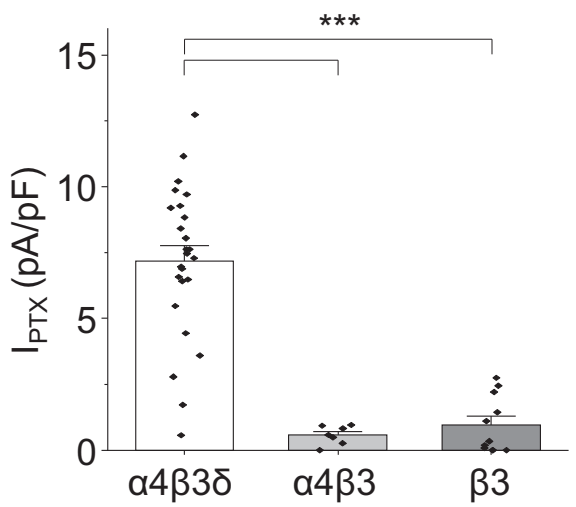

predominant receptor population expressed is $\alpha 4 \beta 3 \delta$, and that this isoform consequently underlies the spontaneous current in these cells.

Extracellular motifs in $\beta 3$ subunits are essential for spontaneous activity. Key differences in structure between $\beta 2$ and $\beta 3$ subunits are likely to underlie why only $\beta 3$ subunits support

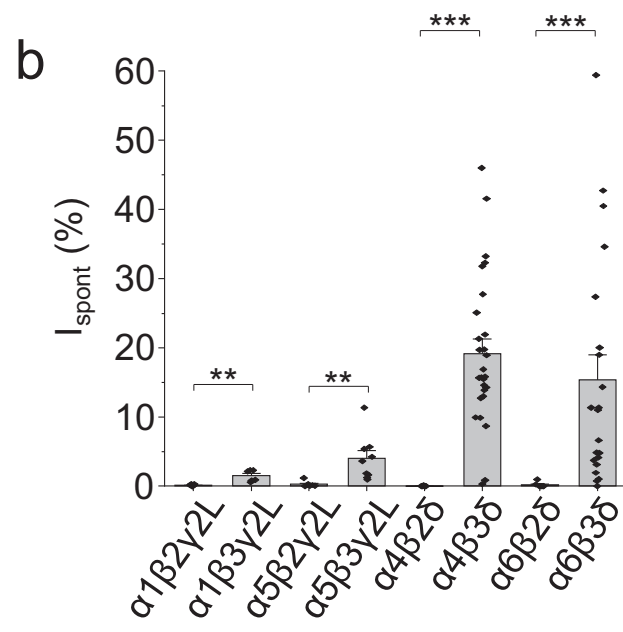

d

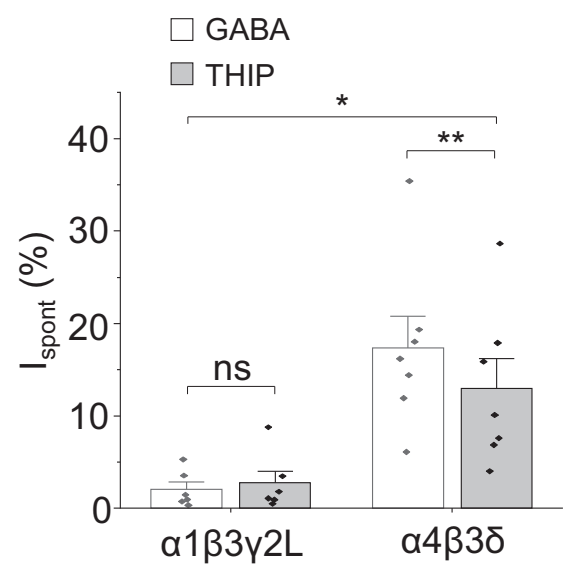

f

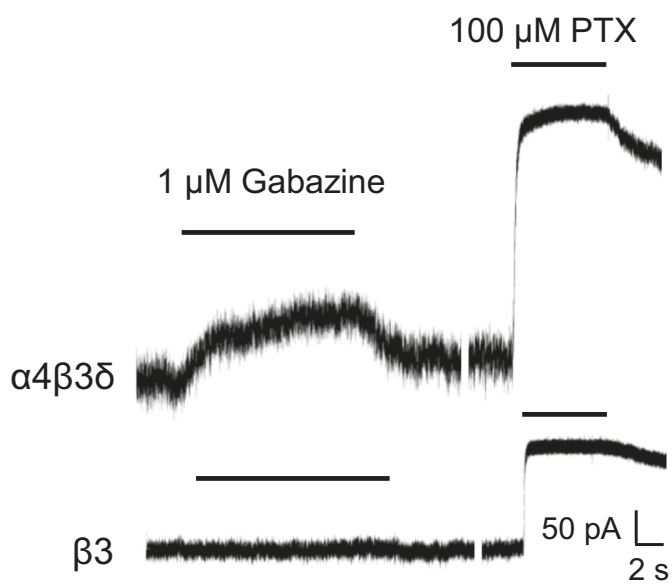

spontaneous activity of $\mathrm{GABA}_{\mathrm{A}} \mathrm{Rs}$. To identify the domains involved we created chimeric subunits, by first exchanging the entire N-terminal extracellular domain (ECD) between $\beta 2$ and $\beta 3$ subunits (Fig. 2a). This exchange completely switched the spontaneous properties of receptors; replacing $\beta 2$ ECD with that of $\beta 3$ in the $\alpha 4 \beta 2^{\beta 3(E C D)} \delta$ receptor gave rise to similar levels of spontaneous activity as wild-type $\alpha 4 \beta 3 \delta$, while the converse 
Fig. 1 $\mathbf{\beta 3}$ subunits are required for heteromeric $\mathbf{G A B A}_{\mathbf{A}} \mathbf{R}$ spontaneous activity. a Determining spontaneous receptor activity in HEK cells expressing $\alpha 4 \beta 3 \delta$. $I_{\text {Max }}$ is the current evoked by a saturating concentration of agonist (GABA, $500 \mu M$ ), while IPTX is the reduced holding current caused by a saturating concentration of PTX $(100 \mu \mathrm{M})$ and is equivalent to the current caused by spontaneous $\mathrm{GABA}_{A} \mathrm{R}$ activity. These parameters were used to calculate $I_{\text {spont }}$ (see Methods). b Bar graph of $\mathrm{I}_{\text {spont }}$ for a variety of receptor isoforms expressed in HEK cells $(\alpha 1 \beta 2 \gamma 2 \mathrm{~L} / \alpha 1 \beta 3 \gamma 2 \mathrm{~L}: n$ (cells) $=7 / 6$, ${ }^{\star \star} P=0.0093$, two-sided unpaired $t$-test; $\alpha 5 \beta 2 \gamma 2 \mathrm{~L} / \alpha 5 \beta 3 \gamma 2 \mathrm{~L}: n=7 / 9,{ }^{\star \star \star} P=0.00035$, two-sided Mann-Whitney test; $\alpha 4 \beta 2 \delta / \alpha 4 \beta 3 \delta: n=6 / 27$,

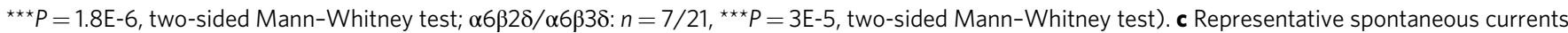
for $\alpha 4 \beta 1 \delta, \alpha 4 \beta 2 \delta$ and $\alpha 4 \beta 3 \delta$ receptors, determined using PTX $(100 \mu \mathrm{M})$. d Using the 'super agonist' THIP ( $3 \mathrm{mM})$ to calculate $\mathrm{I}_{\text {spont }}$ of $\alpha 4 \beta 3 \delta$ receptors ( $\alpha 1 \beta 3 \gamma 2 \mathrm{~L}: n=6, P=0.26$ two-sided paired $t$-test; $\alpha 4 \beta 3 \delta: n=7 ;{ }^{\star \star} P=0.0090$ two-sided paired $t$-test. Between-receptor comparison: ${ }^{\star} P=0.014$, twosided unpaired $t$-test). e HEK cells transfected with three $(\alpha 4, \beta 3$ and $\delta$ ), two ( $\alpha 4$ and $\beta 3$ ) or one ( $\beta 3$ ) cDNA to provide preferential conditions for the formation of triheteromeric, diheteromeric and homomeric receptors, respectively. Measurement of IPTX was normalised to cell capacitance. Triheteromers displayed significantly larger current densities than diheteromers ( $\left.{ }^{\star \star \star} P=0.00034\right)$ and homomers $\left({ }^{\star \star \star} P=2.8 \mathrm{E}-5\right)$. Current densities for diheteromers and homomers did not differ ( $P=1$; Kruskall-Wallis with Dunn's post-hoc test; $\alpha 4 \beta 3 \delta: n=25 ; \alpha 4 \beta 3: n=7 ; \beta 3: n=11$ ). f The orthosteric antagonist gabazine $(1 \mu \mathrm{M})$ exhibits inverse agonist properties at triheteromeric (top), but not homomeric, receptors. Data are presented as mean values \pm SEM. ${ }^{\star} P<0.05$; ${ }^{\star \star} P<0.01 ;{ }^{\star \star \star} P<0.001 ;$ ns no significance. Source data are provided as a Source Data file for Fig. 1.

exchange $\left(\alpha 4 \beta 33^{\beta 2(E C D)} \delta\right)$ revealed negligible spontaneous currents, similar to wild-type $\alpha 4 \beta 2 \delta$ receptors (Fig. 2b; Supplementary Table 1).

To identify key determinants within the ECD that underlie the difference in spontaneous activity between $\beta 2$ - and $\beta 3$-containing receptors, we focused on one major difference between the $\beta$ subunits: the ability of $\beta 3$, but not $\beta 2$, to form functional homomers. This homomeric assembly is due to four residues in a cassette of ten within the ECD of the $\beta 3$ subunit: Gly171, Lys173, Glu179 and Arg180, together known as the GKER motif ${ }^{27}$ (specifically, GxKxxxxxER). The equivalent residues in $\beta 2$ are Asp170, Asn172, Thr178 and Lys179 (DNTK) ${ }^{27}$. Whether the GKER motif is also important for spontaneous activity was assessed using $\alpha 4 \beta 3 \delta$ receptors. The $\beta$ subunit extracellular motifs were exchanged and expressed as $\alpha 4 \beta 3^{\mathrm{DNTK}_{\delta}}$ and $\alpha 4 \beta 2^{\mathrm{GKER}} \delta$ (Fig. 2c). For $\alpha 4 \beta 2^{\mathrm{GKER}} \delta$ receptors, similar levels of spontaneous activity were measured compared to wild-type $\alpha 4 \beta 3 \delta$. By contrast, $\alpha 4 \beta 3^{\mathrm{DNTK}} \delta$ receptors exhibited negligible spontaneous activity, equivalent to wild-type $\alpha 4 \beta 2 \delta$ receptors (Fig. $2 \mathrm{~d}$, Supplementary Table 1). Thus, this ECD assembly motif plays a critical role in permitting spontaneous activity in $\mathrm{GABA}_{\mathrm{A}} \mathrm{Rs}$.

To distinguish between its role in mediating homooligomerisation and spontaneous gating in heteromeric receptors, $\beta 3$ subunits were created where each half of GKER was mutated to its $\beta 2$ equivalent. Dividing DNTK in $\alpha 4 \beta 3^{\mathrm{DN}} \delta$ and $\alpha 4 \beta 3^{\mathrm{TK}} \delta$ receptors substantially reduced, but did not ablate, spontaneous activity compared to $\alpha 4 \beta 3 \delta$ receptors (Fig. 2e; Supplementary Fig. 1c; Supplementary Table 1). However, when expressed as homomers ( $\beta 3^{\mathrm{DN}}$ or $\left.\beta 3^{\mathrm{TK}}\right)$ there was no disruption to homooligomerisation indicated by the unaltered $\mathrm{I}_{\text {spont }}$ (normalised to $100 \mu \mathrm{M}$ pentobarbital) compared to wild-type $\beta 3$ assemblies (Fig. 2f; Supplementary Fig. 1d). Therefore, all four residues are required for full spontaneous activity in $\alpha 4 \beta 3 \delta$ heteromers, while either pair of residues is sufficient for $\beta 3$ homomeric assembly and spontaneous gating. Hence, homo-oligomerisation of $\beta 3$ subunits and spontaneous gating of heteromeric $\alpha 4 \beta 3 \delta$ receptors depend differentially on the GKER motif. Furthermore, these results indicate that the spontaneous current from $\alpha 4 \beta 3 \delta$ transfected cells cannot involve a significant contribution from $\beta 3$ homomers.

To locate the GKER motif within the $\alpha 4 \beta 3 \delta \quad G_{A B A} R$ structure, we constructed a homology model (Fig. $2 \mathrm{~g}$ ) derived from the cryo-EM structure of the $a 1 \beta 3 \gamma 2$ receptor $^{5}$. Studies using both free subunits and concatemeric constructs have suggested that recombinant $\alpha 4 \beta \delta$ receptors can assemble with various stoichiometries and subunit arrangements ${ }^{28,29}$. However, as both functional and structural data support the inclusion of a single $\delta$ subunit in freely assembled recombinant receptors (arranged $\alpha-\beta-\alpha-\beta-\delta$ clockwise from the extracellular space) ${ }^{30,31}$, this was the most parsimonious basis for our homology model. This revealed the GKER motif positioned at the non-GABAbinding $\alpha^{+}-\beta^{-}$and $\delta^{+}-\beta^{-}$interfaces, connecting $\beta$ strands 8 and 9 (Fig. 2g).

Additional subunits affecting $\mathrm{GABA}_{\mathrm{A}} \mathrm{R}$ spontaneous activity. Although $\beta 3$ subunits are important for spontaneous activity of $\alpha \beta \gamma$ and $\alpha \beta \delta$ receptors, it is likely that other subunits also play a role, given that receptors incorporating $\alpha 4 / 6$ and/or $\delta$ subunits showed increased spontaneous activity (Fig. 1b). To investigate, spontaneous currents mediated by $\alpha 1 \beta 3 \delta$ and $\alpha 4 \beta 3 \gamma 2 \mathrm{~L}$ receptors were compared to $\alpha 4 \beta 3 \delta$ (Fig. 3a; Supplementary Fig. 1a; Supplementary Table 1$)$. Both $\alpha 1 \beta 3 \delta$ and $\alpha 4 \beta 3 \gamma 2 \mathrm{~L}$ receptors exhibited negligible spontaneous activity, indicating that incorporation of both $\alpha 4$ (or $a 6$ ) and $\delta$, together with $\beta 3$ subunits, is necessary for agonist-independent gating.

To determine if the ECDs of the non- $\beta$ subunits are important, chimeras were generated which replaced the $\alpha 4$ and $\delta$ ECDs with those from $\alpha 1\left(\alpha 4^{\alpha 1(E C D)}\right)$ and $\gamma 2 \mathrm{~L}\left(\delta^{\gamma 2 L(E C D)}\right)$, respectively. Expressing these chimeric subunits in $\alpha 4^{\alpha 1(E C D)} \beta 3 \delta$ and $\alpha 4 \beta 3 \delta^{\gamma 2 \mathrm{~L}(\mathrm{ECD})}$ receptors reduced, but did not abolish, spontaneous activity (Fig. 3b; Supplementary Table 1). These chimeric receptors did not show the same reduction in spontaneous current as wild-type $\alpha 1 \beta 3 \delta$ and $\alpha 4 \beta 3 \gamma 2 \mathrm{~L}$ receptors, suggesting that the ECDs in $\alpha 4$ and $\delta$, while contributing towards spontaneity, are not the only domains in these subunits that control spontaneous gating.

As the $\beta 3$ GKER motif's importance for $\mathrm{GABA}_{\mathrm{A}} \mathrm{R}$ assembly and spontaneous activity most likely involves interactions with adjacent subunits ${ }^{27}$, we examined residues in the $a 4$ and $\delta$ subunit ECDs that could interact with GKER across the $\alpha^{+}-\beta^{-}$ and $\delta^{+}-\beta^{-}$interfaces. We focused on residues surrounding and including loop $\mathrm{C}$ of $\alpha, \delta$ and $\gamma 2 \mathrm{~L}$ subunits, as this structure projects like a 'structural clasp' from the principal subunit side, spanning the subunit interface, and potentially interacting with the complementary face of juxtaposed $\beta$ subunits. Accordingly, loop $C$ and surrounding residues of the $\alpha 4$ subunit (T200 to L217) were exchanged for the equivalent residues in $\alpha 1$ subunits (I201 to L218). A similar switch of $\delta$ subunit residues (T206 to S222) to their equivalents in $\gamma 2 \mathrm{~L}$ (T209 to S224) was also performed. Compared with $\alpha 4 \beta 3 \delta$ receptors, spontaneity was unaltered by exchanging the a4 domain with that from $\alpha 1$ $\left(\alpha 4^{\alpha 1(l o o p ~ C)} \beta 3 \delta\right.$ receptors); however, a reduction in spontaneous current was evident after the exchange of the $\delta$ domain with that from $\gamma 2 \mathrm{~L}\left(\alpha 4 \beta 3 \delta \gamma^{2 L}\right.$ (loop C) receptors; Fig. 3c; Supplementary Table 1). Notably, the amino acid homology of the exchanged domain is greater between $\alpha 1$ and $\alpha 4(61 \%)$ compared to $\gamma 2 \mathrm{~L}$ and $\delta(29 \%)$ subunits (Fig. 3d, e). 
a

$\beta 2^{\beta 3(E C D)}$

$\beta 3^{\beta 2(E C D)}$
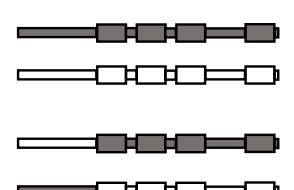

C

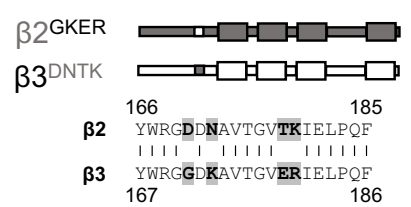

e

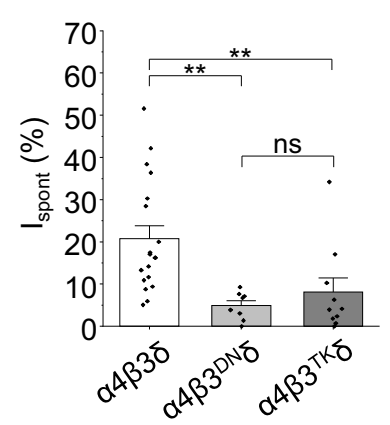

g

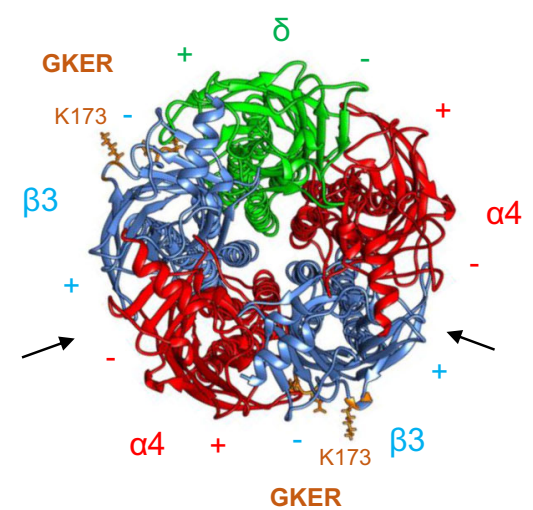

b

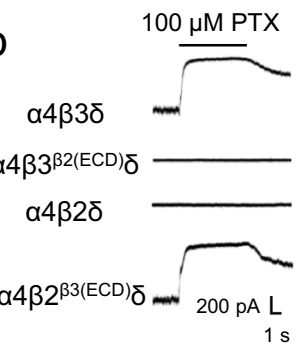

d

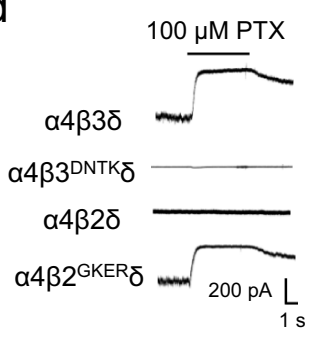

f

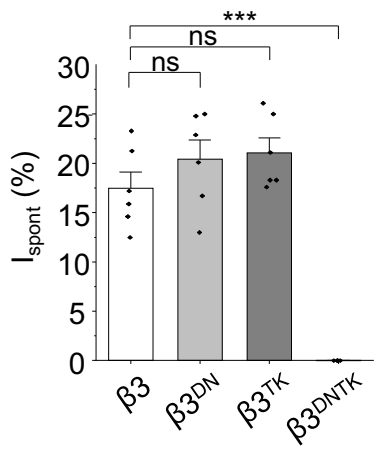

a4
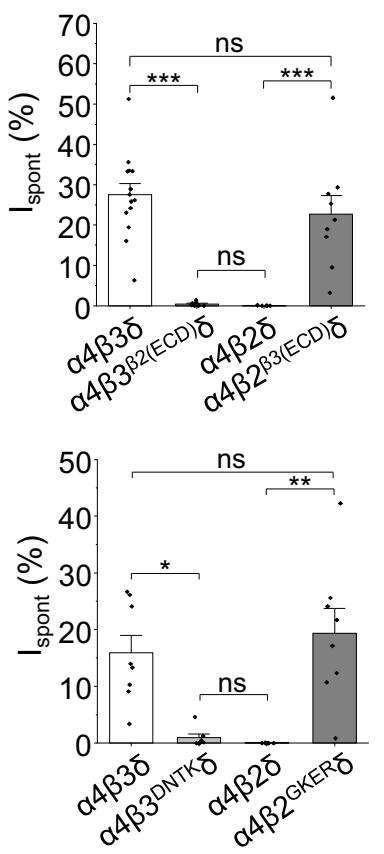

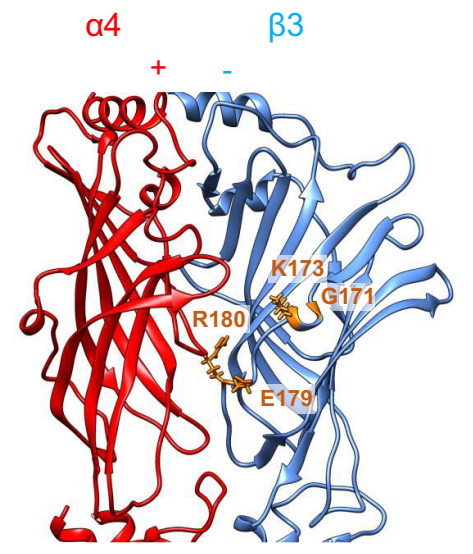

To search for the structural determinants that could account for why a 4 subunits are more effective at inducing spontaneous activity than $\alpha 1$, the $\alpha 4 \beta 3 \delta$ receptor model was used to explore sequence variation between these subunits that may underlie differential interaction with the $\beta 3$ GKER motif. One prominent difference is an arginine residue (R100) in $\alpha 4$ replaced by a histidine (H101) in al (Fig. 3f). Expression of $\alpha_{4}{ }^{\mathrm{R} 100 \mathrm{H}} \beta 3 \delta$ revealed significantly lower levels of spontaneous activity compared to wild-type $\alpha 4 \beta 3 \delta$ (Fig. 3g; Supplementary Table 1), indicating that $\alpha 4^{\mathrm{R} 100}$ alone, and/or its interaction with the $\beta 3$ GKER motif (possibly through an arg-arg interaction) is important for regulating spontaneous receptor activity. Histidine 101 in $\alpha 1$ is also critical for the binding of benzodiazepines at the $a^{+}-\gamma^{-}$interface ${ }^{32}$, corroborating this residue's importance in modulating receptor activity.

In summary, the subunit composition of the pentamer is critical for determining spontaneous activity, with subunit interactions at the $\alpha^{+}-\beta^{-}$and $\delta^{+}-\beta^{-}$ECD interfaces 
Fig. $2 \boldsymbol{\beta} 3$ subunit ECD residues responsible for spontaneity of heteromeric $\mathbf{G A B A}_{\mathbf{A}} \mathbf{R s}$. a Schematic of $\beta 2 / 3$ chimeras with exchanged ECDs. $\mathbf{b}$ Left: $I_{\mathrm{PTX}}$ for wild type and chimeric $\alpha 4 \beta \delta$ receptors. Right: $I_{\text {spont }}$ of wild type and chimeric $\alpha 4 \beta \delta$ receptors. Wild-type $\alpha 4 \beta 3 \delta I_{\text {spont }}$ was significantly larger than $\alpha 4 \beta 3^{\beta 2(E C D)} \delta\left({ }^{\star \star \star} P=8.7 \mathrm{E}-7\right)$ and no different from $\alpha 4 \beta 2^{\beta 3(E C D)} \delta(P=0.62)$. Wild-type $\alpha 4 \beta 2 \delta$ was significantly smaller than $\alpha 4 \beta 2^{\beta 3(E C D)} \delta$

$\left.{ }^{\star \star \star} P=0.00088\right)$ and no different from $\alpha 4 \beta 3^{\beta 2(E C D)} \delta\left(P=1\right.$; one-way ANOVA with Tukey's post-hoc test; $\alpha 4 \beta 3 \delta: n=14 ; \alpha 4 \beta 3^{\beta 2(E C D)} \delta: n=8 ; \alpha 4 \beta 2 \delta$ : $n=7 ; \alpha 4 \beta 2^{\beta 3(E C D)} \delta: n=9$ ). c Schematic of chimeras with the GKER/DNTK motif exchanged between the $\beta 2 / 3$ subunits. Primary sequences for $\beta 2$ and $\beta 3$ are shown below with GKER and DNTK residues highlighted. d Left: I IPT for wild type and ECD motif-exchanged $\alpha 4 \beta \delta$ receptors. Right: $I_{\text {spont }}$ of wild type and ECD motif-exchanged $\alpha 4 \beta \delta$ receptors. Wild-type $\alpha 4 \beta 3 \delta I_{\text {spont }}$ was significantly larger than $\alpha 4 \beta 3^{\mathrm{DNTK}} \delta\left({ }^{\star} P=0.038\right)$ and no different from $\alpha 4 \beta 2{ }^{\mathrm{GKER}} \delta$ $(P=1)$. Wild-type $\alpha 4 \beta 2 \delta$ was significantly smaller than $\alpha 4 \beta 2^{\mathrm{GKER}} \delta\left({ }^{\star \star} P=0.0010\right)$ and no different from $\alpha 4 \beta 3^{\mathrm{DNTK}} \delta(P=1 ;$ Kruskall-Wallis with Dunn's post-hoc test; $\alpha 4 \beta 3 \delta: n=8 ; \alpha 4 \beta 3^{\mathrm{DNTK}} \delta: n=7 ; \alpha 4 \beta 2 \delta: n=7 ; \alpha 4 \beta 2^{\mathrm{GKER}} \delta: n=8$ ). e I $_{\text {spont }}$ of $\alpha 4 \beta 3 \delta$ receptors expressing partial exchange of the GKER/ DNTK motif. Wild-type $\alpha 4 \beta 3 \delta I_{\text {spont }}$ was significantly larger than $\alpha 4 \beta 3^{D N} \delta\left({ }^{\star} P=0.0022\right)$ and $\alpha 4 \beta 3^{T K} \delta\left({ }^{\star} P=0.0064\right)$. Mutant receptors were not significantly different ( $P=1$; Kruskall-Wallis with Dunn's post-hoc test; $\left.\alpha 4 \beta 3 \delta: n=19 ; \alpha 4 \beta 3^{\mathrm{DN}} \delta: n=8 ; \alpha 4 \beta 3^{\mathrm{TK}} \delta: n=10\right)$. $\mathbf{f} \mathrm{I}_{\text {spont }}$ of wild-type $\beta 3$ homomeric receptors, and those containing a partial or full exchange of the GKER/DNTK motif. As $\beta 3$ homomers are insensitive to GABA, pentobarbital (100 $\mu M$ ) was used to generate $I_{\text {Max. }} \beta 3^{D N T K}$ subunits did not form functional receptors. Wild-type $\beta 3$ homomers were no different from $\beta 3^{D N}(P=0.54)$ or $\beta 3^{\text {TK }}$ $\left(P=0.37 ;\right.$ Kruskal-Wallis with Dunn's post-hoc test; $\left.\beta 3: n=6 ; \beta 3^{D N}: n=6 ; \beta 3^{\text {TK}}: n=6 ; \beta 3^{\text {DNTK }}: n=5\right)$. $\mathbf{g}$ Homology model of the $\alpha 4 \beta 3 \delta$ receptor shown in plan view (left) and from the side at the $\alpha^{+}-\beta^{-}$interface, highlighting the GKER residues in the $\beta 3$ subunits. Principal $(+)$ and complementary $(-)$ faces are indicated. Arrows show the orthosteric GABA binding sites. Data are presented as mean values $\pm \mathrm{SEM} .{ }^{\star} P<0.05 ;{ }^{\star \star} P<0.01 ;{ }^{\star \star \star} P<0.001 ; \mathrm{ns}$ no significance. Source data are provided as a Source Data file for Fig. 2.

contributing to the ability of the receptor to gate spontaneously. However, exchanging ECDs did not abolish spontaneous activity, suggesting other determinants exist in $\alpha 4$ and $\delta$ subunits.

Spontaneous gating is associated with increased GABA potency. To identify the mechanisms underlying spontaneity, the relationship between ligand-gating and spontaneous activity was investigated. If receptors are capable of opening in the absence of agonist, then it is plausible they may be more responsive to agonist $^{33}$. GABA concentration-response curves were constructed for wild-type $\alpha 4 \beta 3 \delta / \gamma 2 \mathrm{~L}$ receptors, and for corresponding mutant receptors with altered spontaneous activity. The first receptor variant selected was the non-spontaneous $\alpha 4 \beta 3^{\mathrm{DNTK}_{\delta}}$ (Fig. $4 \mathrm{a}$ ). The GABA concentration-response curve for $\alpha 4 \beta 3^{\text {DNTK }} \delta$ was right-shifted compared with wild-type $\alpha 4 \beta 3 \delta$ receptors $\left(\mathrm{EC}_{50} \mathrm{~s}\right.$ of 1.5 and $0.4 \mu \mathrm{M}$, respectively; Fig. $4 \mathrm{~b}$ ). To explore further, the mutation $\mathrm{K} 279 \mathrm{~T}$ in the $\beta 3 \mathrm{M} 2-\mathrm{M} 3$ linker was used since this markedly increases GABA potency at $\alpha 1 \beta 3 \gamma 2 \mathrm{~L}$ receptors ${ }^{34}$. For $\alpha 4 \beta 3^{\mathrm{K} 279 \mathrm{~T}} \gamma 2 \mathrm{~L}$, high levels of spontaneity were apparent compared to negligible constitutive activity for $\alpha 4 \beta 3 \gamma 2 \mathrm{~L}$ (Fig. $4 \mathrm{c}$, Supplementary Table 1). GABA was also significantly more potent at $\alpha 4 \beta 3{ }^{\mathrm{K} 279 \mathrm{~T}} \gamma 2 \mathrm{~L}$, with an $\mathrm{EC}_{50} 35$-fold lower $(0.4 \mu \mathrm{M})$ compared to wild type $(14 \mu \mathrm{M}$; Fig. $4 \mathrm{~d})$.

These experiments suggest that spontaneous activity is associated with increased GABA potency, potentially reflecting lowered activation energy for channel opening. This is consistent with $\delta$-containing receptors, which are more sensitive to GABA, also displaying greater spontaneous activity than their $\gamma$ containing counterparts (Fig. 1d).

Phosphorylation status of $\boldsymbol{\beta 3}$ subunits affects spontaneous activity. The large intracellular domain (ICD) between M3 and M4 of $\mathrm{GABA}_{\mathrm{A}} \mathrm{Rs}$ is a location for phosphorylation by protein kinases and for modifying receptor trafficking and function ${ }^{35-38}$, which could be important for controlling spontaneous activity. Indeed, activation of protein kinases can increase spontaneous currents mediated by $\alpha 4 \beta 3 \delta$ receptors $^{18}$, but the phosphorylation site is unknown. We investigated phosphorylation of the $\beta 3$ subunit, given its importance for spontaneous activity and that phosphorylation sites have been identified involving adjacent serines, S408 and S409, within the large $\mathrm{ICD}^{36}$. Using serine to alanine substitutions to prevent $\beta 3$ phosphorylation in $\alpha 4 \beta 3^{\mathrm{S} 408 \mathrm{~A}} \delta$ and $\alpha 4 \beta 3^{\mathrm{S} 409 \mathrm{~A}} \delta$ receptors, spontaneous activity was reduced by $67 \%$ and $82 \%$, respectively. Mutating both residues $\left(\alpha 4 \beta 3^{\mathrm{S} 408 \mathrm{~A}, \mathrm{~S} 409 \mathrm{~A} \delta)}\right.$ reduced the spontaneous current by $39 \%$ (Fig. 5a, Supplementary Fig. 3a; Supplementary Table 1). To ensure these effects were due to receptor phosphorylation status, the cell-permeable, broad-spectrum kinase inhibitor staurosporine $(200 \mathrm{nM})$ was applied to $\alpha 4 \beta 3 \delta$ receptors and the $\mathrm{I}_{\text {spont }}$ measured over $20 \mathrm{~min}$. Consistent with previous studies showing rapid effects of kinase inhibitors on spontaneous current ${ }^{18}$, $\mathrm{I}_{\text {spont }}$ decreased significantly after 1 min exposure and declined further during the $20 \mathrm{~min}$ window. Despite some rundown in spontaneous activity under control conditions, $\mathrm{I}_{\text {spont }}$ was significantly smaller in staurosporine compared to control (Fig. 5b, c). To confirm that staurosporine was affecting the phosphorylation status of S408 and S409, it was also applied to phospho-null

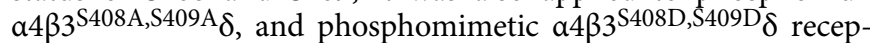
tors (Fig. 5c) where it had no effect, with $\mathrm{I}_{\text {spont }}$ similar to control.

Both S408 and S409 are phosphorylated by various serine/ threonine kinases, including cAMP-dependent protein kinase (PKA), protein kinase $\mathrm{C}(\mathrm{PKC})$, protein kinase $\mathrm{G}(\mathrm{PKG})$ and $\mathrm{Ca}^{2+} /$ calmodulin-dependent protein kinase II (CaMKII) ${ }^{36,38-40}$ To identify whether specific protein kinases are responsible for regulating the spontaneous current, the following selective kinase inhibitors were used: PKA inhibitor peptide 14-22 $(1 \mu \mathrm{M})$, bisindolylmaleimide-I $(200 \mathrm{nM})$ and KT $5823(1 \mu \mathrm{M})$ to inhibit PKA, PKC and PKG, respectively. Inhibitors were individually included in the patch electrode solution and allowed to dialyse into the cell for $2 \mathrm{~min}$ before $\mathrm{I}_{\text {spont }}$ was measured. Each inhibitor reduced the spontaneous current of $\alpha 4 \beta 3 \delta$ receptors compared to controls (Fig. 5d-f; Supplementary Fig. 3b). However, internal application of the PKA-activator $8-\mathrm{Br}$ cAMP $(1 \mathrm{mM})$ did not affect $\mathrm{I}_{\text {spont }}$ (Fig. 5g). This accords with the lack of difference in $\mathrm{I}_{\text {spont }}$ between $\alpha 4 \beta 3^{\mathrm{S} 408 \mathrm{D}, \mathrm{S409D} \delta}$ and wild-type $\alpha 4 \beta 3 \delta$ receptors (Supplementary Fig. 3c), suggesting that S408 and S409 are fully phosphorylated under control conditions.

Overall, these results demonstrate that PKA, PKC and PKG can target serine phosphorylation sites to modulate $\alpha 4 \beta 3 \delta$ receptor-mediated spontaneous currents. Phosphorylation by CaMKII was also examined since this kinase can phosphorylate not only S408 and S409 but also S383 ${ }^{39,40}$. However, the $\beta 3^{\mathrm{S} 383 \mathrm{~A}}$ mutant had no effect on spontaneous activity in $\alpha 4 \beta 3^{\mathrm{S} 383 \mathrm{~A}} \delta$ receptors compared with wild type (Supplementary Fig. 3d, Supplementary Table 1). Moreover, internally applying the selective CaMKII inhibitor KN-62 $(3 \mu \mathrm{M})$ also had no effect on $\mathrm{I}_{\text {spont }}$ (Supplementary Fig. 3b, e). These results imply that CaMKII activity is unlikely to modulate spontaneous activity of recombinant receptors expressed in HEK cells, although this may differ in a neuronal environment ${ }^{41}$. 
a

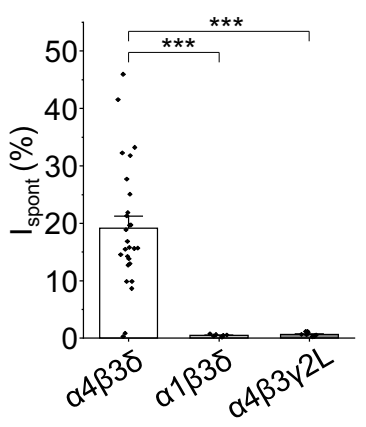

b

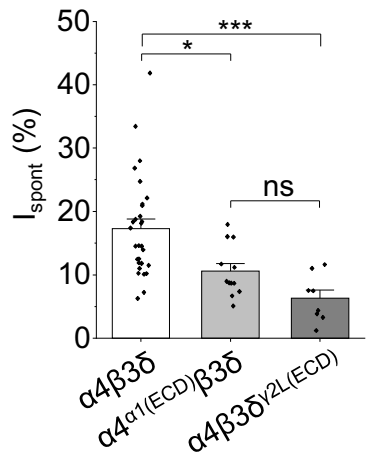

C

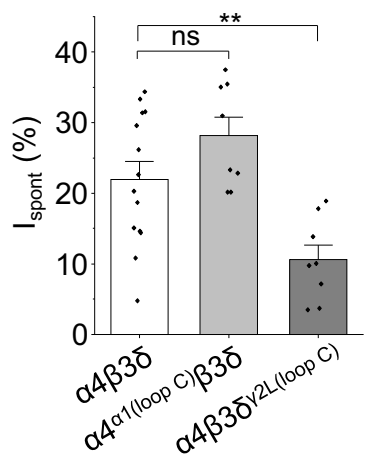

d
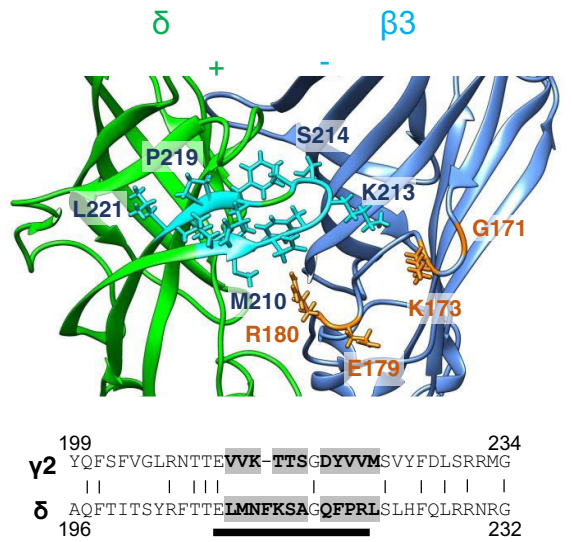

f

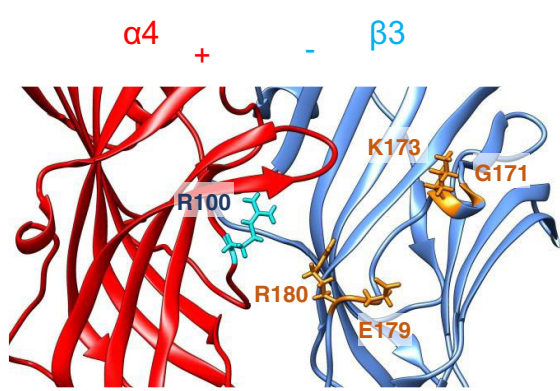

e

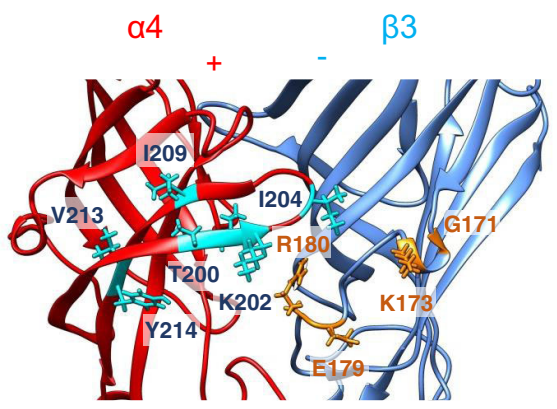

a1 ${ }^{188}$ NQYDLLGQTVDSGIVQSSTGEYVVMTTHFHLKRKIGYFVIQ

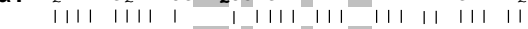
a4 VQYDLIGQTVSSETIKSITGEYIVMTVYFHLRRKMGYFMIQ
187

g

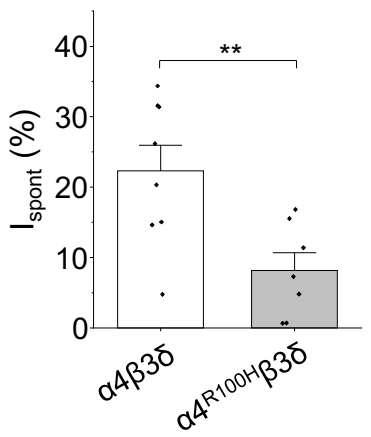

Fig. $3 \alpha 4$ and $\delta$ ECDs are important for spontaneous activity. a $I_{\text {spont }}$ of extrasynaptic-type $\alpha 4 \beta 3 \delta$ receptors, and receptors where a single subunit was exchanged for a synaptic-type subunit. $\mathrm{I}_{\text {spont }}$ was significantly reduced when $\alpha 1$ replaced $\alpha 4\left({ }^{\star \star \star} P=2.4 \mathrm{E}-5\right)$ and when $\gamma 2 \mathrm{~L}$ replaced $\delta(P=2.5 \mathrm{E}-6$; one-way ANOVA with Tukey's post-hoc test; $\alpha 4 \beta 3 \delta: n=27 ; \alpha 1 \beta 3 \delta: n=7 ; \alpha 4 \beta 3 \gamma 2 \mathrm{~L}: n=10)$ ). $\mathbf{b}$ Ispont $_{\text {s }} \alpha 4 \beta 3 \delta$ receptors and receptors where the $\alpha 4$ or $\delta$ ECDs were replaced by those from $\alpha 1$ and $\gamma 2 \mathrm{~L}$, respectively. $\mathrm{I}_{\text {spont }}$ was significantly reduced when $\alpha 4^{\alpha 1(\mathrm{ECD})}$ replaced $\alpha 4\left({ }^{\star} P=0.014\right)$ and when $\delta^{\gamma 2 \mathrm{~L}(\mathrm{ECD})}$ replaced $\delta$ $\left({ }^{\star \star \star} P=0.00044\right)$; there was no difference between the two mutant receptors $(P=0.35$; one-way ANOVA with Tukey's post-hoc test; $\alpha 4 \beta 3 \delta: n=29 ;$ $\left.\alpha 4^{\alpha 1(E C D)} \beta 3 \delta: n=12 ; \alpha 4 \beta 3 \delta^{\gamma 2 L(E C D)}: n=12\right)$. c Residues that were not conserved in loop $C$ region between $\alpha 4$ and $\alpha 1$, and between $\delta$ and $\gamma 2 L$, were exchanged and $I_{\text {spont }}$ for $\alpha 4 \beta 3 \delta$ receptors incorporating these substitutions $\left(\alpha 4^{\alpha 1(\text { loop C) }}\right.$ and $\left.\delta^{\gamma 2 L(\text { loop C) }}\right)$ was determined. No effect was observed when introducing loop $C$ residues from $\alpha 1$ into $\alpha 4(P=0.21)$, while a significant reduction was observed when introducing loop $C$ residues from $\gamma 2 \mathrm{~L}$ into $\delta$ ${ }^{\star \star} P=0.0098$; one-way ANOVA with Tukey's post-hoc test; $\left.\alpha 4 \beta 3 \delta: n=14 ; \alpha 4^{\alpha 1(\text { loop } C)} \beta 3 \delta: n=8 ; \alpha 4 \beta 3 \delta^{\gamma 2 L(\text { loop } C)}: n=8\right)$. Exchanged residues are shown in cyan in the homology models for the $\delta(\mathbf{d})$ and $\alpha 4$ (e) subunit interfacial site opposing the $\beta 3$ subunit. They are also highlighted in the sequence alignments below. Black bars represent approximate constituent residues of loop C. GKER residues of $\beta 3$ are shown in orange. $\mathbf{f} \alpha 4^{+}-\beta 3^{-}$subunit interface showing $\alpha 4$ R100. $\mathbf{g}$ Ispont $_{\text {s }}$ of wild-type $\alpha 4 \beta 3 \delta$ receptors was significantly larger than receptors expressing the $\alpha 4$ subunit R100H mutation ( ${ }^{\star \star} P=0.0087$, two-sided unpaired $t$-test; $\alpha 4 \beta 3 \delta: n=8 ; \alpha 4^{\mathrm{R} 100 \mathrm{H}} \beta 3 \delta: n=7$ ). Data are presented as mean values $\pm \mathrm{SEM}$. ${ }^{\star} P<0.05 ;{ }^{\star \star} P<0.01 ;{ }^{\star \star \star} P<0.001 ; n \mathrm{n}$ no significance. Source data are provided as a Source Data file for Fig. 3. 
a

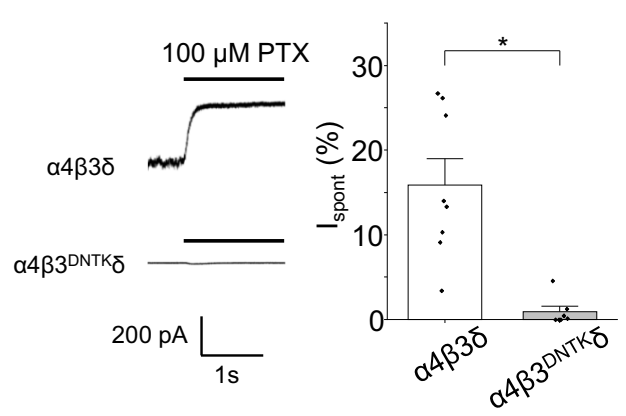

C

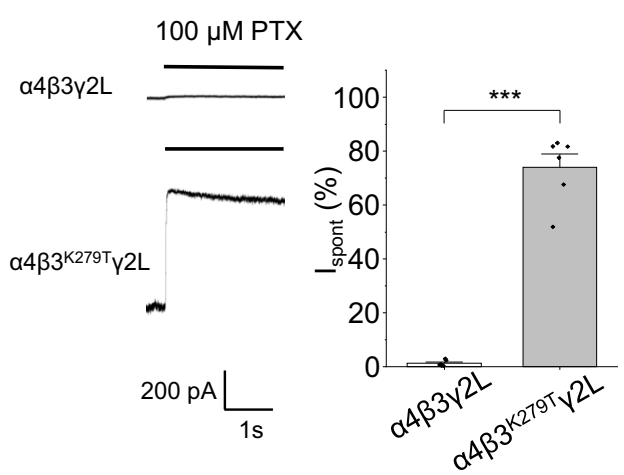

b
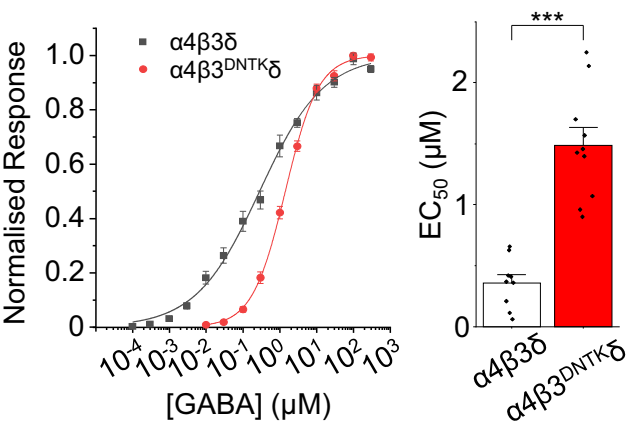

d

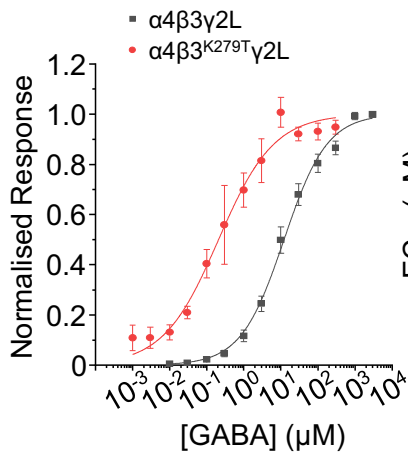

Fig. 4 GABA potency is associated with spontaneous gating of $\mathbf{G A B A}_{\mathbf{A}}$ Rs. a Left: recordings of $\alpha 4 \beta 3 \delta$ and non-spontaneous $\alpha 4 \beta 3^{\mathrm{DNTK}} \delta$ receptors during PTX application. Right: $I_{\text {spont }}$ showing significant reduction when GKER is substituted with DNTK. For comparative purposes, data are reproduced here from Fig. 2 d. b Left: GABA concentration-response curves for $\alpha 4 \beta 3 \delta$ and $\alpha 4 \beta 3^{D N T K} \delta$ receptors. Right: GABA EC 50 values ( ${ }^{\star \star \star} P=9 \mathrm{E}-6$, two-sided unpaired $t$ test; corresponding Hill coefficient values are: $\alpha 4 \beta 3 \delta$ : $\left.0.5 \pm 0.02, n=9 ; \alpha 4 \beta 3^{\mathrm{DNTK}} \delta: 1.0 \pm 0.04, n=10\right)$. c Left: recordings of $\alpha 4 \beta 3 \gamma 2 \mathrm{~L}$ and $\alpha 4 \beta 3^{\mathrm{K} 279 \mathrm{~T}} \gamma 2 \mathrm{~L}$ receptors during PTX application. Right: $\mathrm{I}_{\text {spont }}$ revealing that $\mathrm{K} 279 \mathrm{~T}$ in the M2-M3 linker significantly increases spontaneous activity $\left({ }^{\star \star \star} P=2.5 \mathrm{E}-5\right.$, twosided unpaired $t$-test; $n=6$ ). d Left: GABA concentration-response curves for wild-type $\alpha 4 \beta 3 \gamma 2 \mathrm{~L}$ and $\alpha 4 \beta 33^{279 T} \gamma 2 \mathrm{~L}$ receptors. Right: GABA EC 50 values $\left({ }^{\star} P=0.020\right.$, two-sided unpaired $t$-test; corresponding Hill coefficient values are: $\left.\alpha 4 \beta 3 \gamma 2 \mathrm{~L}: 0.8 \pm 0.03, n=5 ; \alpha 4 \beta 3^{\mathrm{K} 279 \mathrm{~T}} \gamma 2 \mathrm{~L}: 0.8 \pm 0.2, n=6\right)$. Data are presented as mean values \pm SEM. ${ }^{\star} P<0.05 ;{ }^{\star \star \star} P<0.001$. Source data are provided as a Source Data file for Fig. 4.

Allosteric modulators potentiate $\mathrm{GABA}_{\mathrm{A}} \mathrm{R}$ currents in the absence of an orthosteric agonist. Neurosteroids are widely recognised as important endogenous allosteric modulators of $\mathrm{GABA}_{\mathrm{A}} \mathrm{Rs}$, regulating both extrasynaptic and synaptic inhibition ${ }^{42}$. We therefore assessed the effect of the naturally occurring positive modulatory neurosteroids tetrahydro-deoxycorticosterone (THDOC) and allopregnanolone on wild-type and mutant extrasynaptic receptors that exhibit distinct levels of spontaneous activity. Neurosteroids were applied until the holding current reached steady state and, after wash-out, saturating concentrations of GABA and PTX were applied. The change in the holding current in response to neurosteroids was added to $\mathrm{I}_{\mathrm{PTX}}$ for the subsequent calculation of $\mathrm{I}_{\text {spont }}$ (see Methods).

Applying either neurosteroid, at $100 \mathrm{nM}$, increased the $\alpha 4 \beta 3 \delta$ holding current by over $70 \%$ (Fig. $6 a, b$ ) in the absence of an orthosteric ligand. Effectively, these agents were acting as allosteric agonists of the receptor. Although neurosteroids will directly activate $\mathrm{GABA}_{\mathrm{A}} \mathrm{Rs}$ at high concentrations, at $100 \mathrm{nM}$ there was no activation of the non-spontaneous $\alpha 4 \beta 2 \delta$ receptor (Fig. 6a, b), indicating this effect of the neurosteroids is restricted to receptors displaying a propensity to open spontaneously. To establish whether the neurosteroids were acting via their binding site on $\mathrm{GABA}_{\mathrm{A}}$ Rs, we utilised the neurosteroid-insensitive a4 mutant, Q246M, in $\alpha 44^{\mathrm{Q} 246 \mathrm{M}} \beta 3 \delta$ receptors ${ }^{43,44}$. While this mutation had no effect on basal spontaneous current, it ablated the neurosteroid allosteric agonist activity (Fig. 6a, b). We also examined neurosteroid actions at $\alpha 4 \beta 3^{S 409 A} \delta$ receptors since this phosphorylation mutant displays significantly impaired spontaneous activity. Although basal spontaneous currents were much smaller compared to wild type, THDOC and allopregnanolone acted as weak allosteric agonists (Fig. 6a, b), demonstrating that the effects of the positive modulatory neurosteroids correlate with the level of spontaneous activity.

Sulphated neurosteroids, such as pregnenolone sulphate (PS), are also synthesised in the brain but, unlike their potentiating counterparts, they inhibit GABA-induced current ${ }^{45}$. PS $(10 \mu \mathrm{M})$ is a negative allosteric modulator and inhibited spontaneous holding currents of $\alpha 4 \beta 3 \delta, \alpha 4^{\mathrm{Q} 246 \mathrm{M}} \beta 3 \delta$ and $\alpha 4 \beta 3^{\mathrm{S} 409 \mathrm{~A}} \delta$ receptors (Fig. 6c). This inhibition was unaffected by the $\alpha 4$ Q246M mutation due to PS having a binding site distinct from the positive modulatory neurosteroids ${ }^{44}$.

$\mathrm{GABA}_{\mathrm{A}} \mathrm{Rs}$ are also modulated by general anaesthetics. The most widely used intravenous anaesthetic propofol is a potent positive allosteric modulator acting via a discrete binding site to those for potentiating and inhibitory neurosteroids ${ }^{46}$. Recording from $\alpha 4 \beta 3 \delta, \alpha 4 \mathrm{Q}^{\mathrm{Q} 246 \mathrm{M}} \beta 3 \delta$ and $\alpha 4 \beta 3^{\mathrm{S} 409 \mathrm{~A}} \delta$ receptors revealed that propofol $(1 \mu \mathrm{M})$, as with neurosteroids, displayed allosteric agonism, increasing the holding current of all these receptor isoforms but significantly with no effect on the non-spontaneous $\alpha 4 \beta 2 \delta$ receptor (Fig. 6a, b).

Benzodiazepines are subtype-selective modulators of $\mathrm{GABA}_{\mathrm{A}} \mathrm{Rs}$, potentiating $\alpha 1-3,5 \beta \mathrm{x} \gamma 2$ isoforms via their main 
a

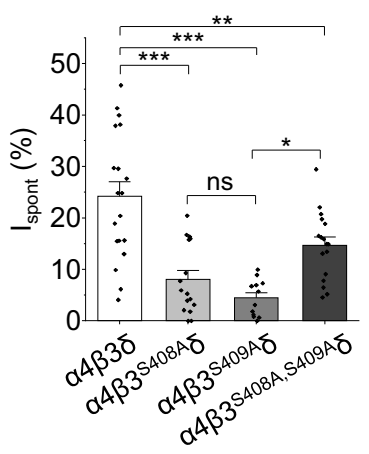

C

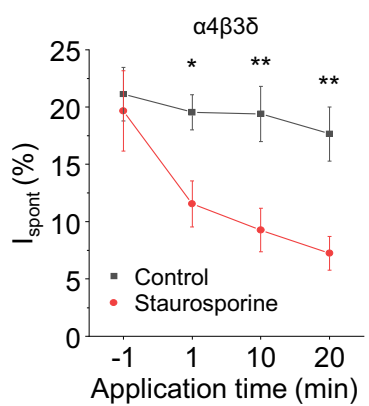

b

$-1 \mathrm{~min} \quad 1 \mathrm{~min} \quad 10 \mathrm{~min} \quad 20 \mathrm{~min}$

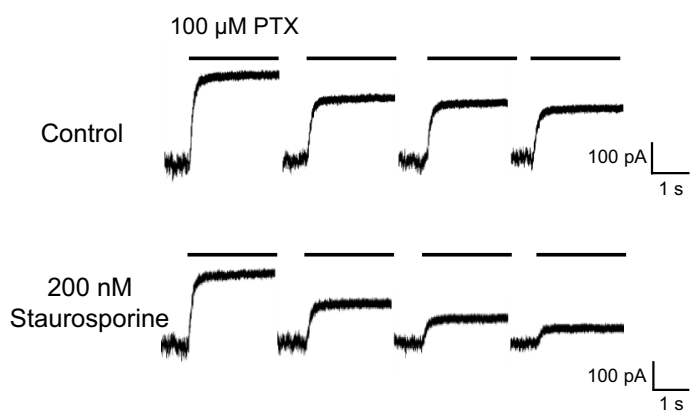

d

e
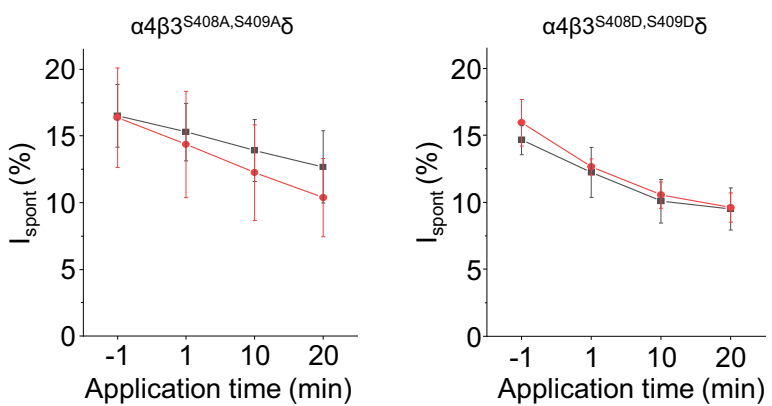

f

g
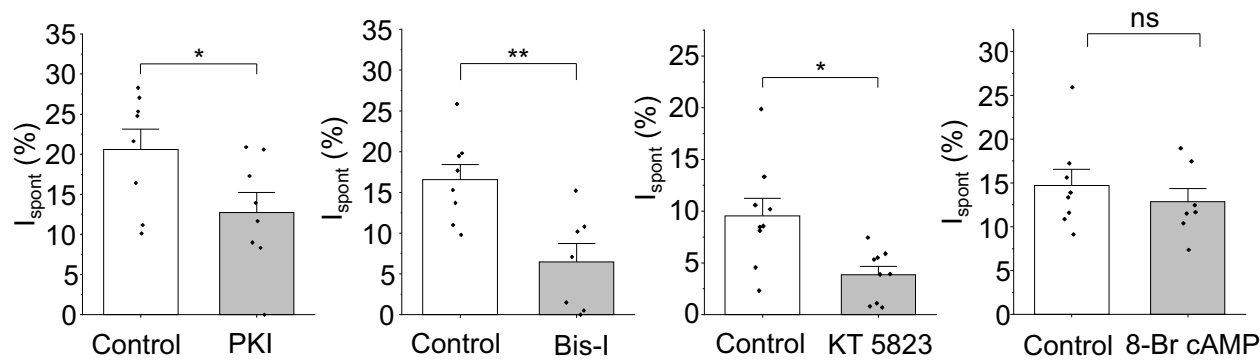

Fig. 5 Phosphorylation of $\boldsymbol{\beta} \mathbf{3}$ subunits regulates spontaneous activity. a $I_{\text {spont }}$ of receptors incorporating $\beta 3$ subunits where either or both phosphorylation sites, S408 and S409, have been mutated. Wild-type $\alpha 4 \beta 3 \delta$ was significantly more spontaneous than $\alpha 4 \beta 3^{S 408 \mathrm{~A}} \delta\left({ }^{\star \star \star} P=3.5 \mathrm{E}-6\right), \alpha 4 \beta 3^{\mathrm{S} 409 \mathrm{~A}} \delta$ $\left({ }^{\star \star \star} P=2.1 \mathrm{E}-7\right)$ and $\left.\alpha 4 \beta 3^{S 408 \mathrm{~A}, \mathrm{~S} 409 \mathrm{~A} \delta\left({ }^{\star} P\right.} P=0.0074\right)$. Individually mutated receptors were no different from each other $(P=0.68)$, and the double mutant was statistically more spontaneous than $\alpha 4 \beta 3^{5409 A} \delta\left({ }^{\star} P=0.012\right)$ but not $\alpha 4 \beta 3^{S 408 A} \delta(P=0.13$, one-way ANOVA with Tukey's post-hoc test; $\alpha 4 \beta 3 \delta$ :

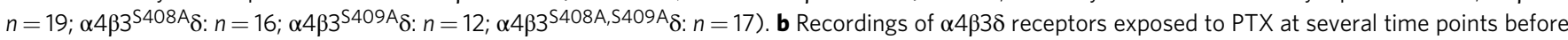
and during application of either control (DMSO-containing) solution or the protein kinase inhibitor staurosporine (200 nM). c $\mathrm{I}_{\text {spont }}$ during a $20 \mathrm{~min}$ application of either DMSO control or $200 \mathrm{nM}$ staurosporine for wild-type, phospho-null $\alpha 4 \beta 3^{S 408 \mathrm{~A}, \mathrm{~S} 409 \mathrm{~A} \delta}$ and phosphomimetic $\alpha 4 \beta 3^{\mathrm{S} 408 \mathrm{D}, \mathrm{S} 409 \mathrm{D} \delta}$ receptors. Only wild-type $\alpha 4 \beta 3 \delta$ receptors displayed smaller $I_{\text {spont }}$ during staurosporine application after 1,10 and 20 min $\left({ }^{\star} P=0.019\right.$; ${ }^{\star \star} P=0.0036$, ${ }^{\star} \star P=0.0029$, mixed ANOVA with Tukey's post-hoc test; $n=6 ; \alpha 4 \beta 3^{S 408 D, S 409 D} \delta+$ staurosporine: $\left.n=5\right)$. d Including selective kinase inhibitors in the patch electrode solution significantly reduced spontaneous currents of $\alpha 4 \beta 3 \delta$ receptors: PKA inhibitor peptide $14-22\left(P K I, 1 \mu M ;{ }^{\star} P=0.043 ; n=8\right)$, e bisindolylmaleimide-I (Bis-I, $200 \mathrm{nM} ;{ }^{\star \star} P=0.0039$; control: $n=8$; Bis-I: $\left.n=7\right)$ and $\mathbf{f}$ KT $5823\left(1 \mu \mathrm{M}\right.$; $\left.{ }^{\star \star} P=0.0076 ; n=9\right)$ to inhibit PKA, PKC and PKG, respectively. Internally applied PKA-activator $8-B r$ cAMP $(1 \mathrm{mM})$ did not affect spontaneous activity $(P=0.46 ;$ control: $n=8 ; 8-B r$ cAMP: $n=7)$. Kinase modulators were compared with appropriate vehicle controls. All comparisons from $\mathbf{d}$-g were two-sided unpaired $t$-tests, Data are presented as mean values \pm SEM. ${ }^{\star} P<0.05$; ${ }^{\star \star} P<0.01 ;{ }^{\star \star \star} P<0.001$; ns no significance. Source data are provided as a Source Data file for Fig. 5.

binding site located at the $\alpha^{+}-\gamma^{-}$subunit interface ${ }^{47,48}$. Despite the low level of spontaneity of $\alpha 1 \beta 3 \gamma 2 \mathrm{~L}$ receptors, the holding current was increased by flurazepam $(300 \mathrm{nM})$, but not in cells expressing the benzodiazepine-insensitive ${ }_{\alpha}{ }^{\mathrm{H} 101 \mathrm{R}} \beta 3 \gamma 2 \mathrm{~L}$ receptor (Fig. 6d) ${ }^{32}$. This concurs with previous work reporting that benzodiazepines can enhance spontaneous currents of $\mathrm{GABA}_{\mathrm{A}} \mathrm{Rs}^{11,12}$.

Our results demonstrate that physiologically relevant concentrations of both positive and negative allosteric modulators can affect
$\mathrm{GABA}_{\mathrm{A}} \mathrm{R}$-mediated currents in the absence of orthosteric agonism. To explore the underlying mechanism, we used single-channel recording from $\alpha 4 \beta 3 \delta$ receptors expressed in outside-out patches from HEK cells. Recording in the absence of GABA revealed spontaneous single-channel currents (Fig. 7c) that were modulated by $100 \mathrm{nM}$ THDOC and blocked by $100 \mu \mathrm{M}$ PTX. Spontaneous currents exhibited brief open durations, rarely forming bursts of channel activity. Such bursts that were evident usually occurred in the presence of THDOC (Fig. 7c). The open time distributions were 
a

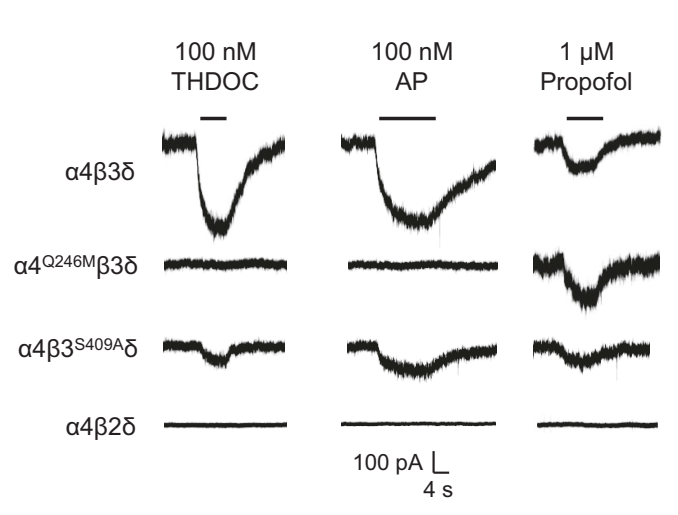

C

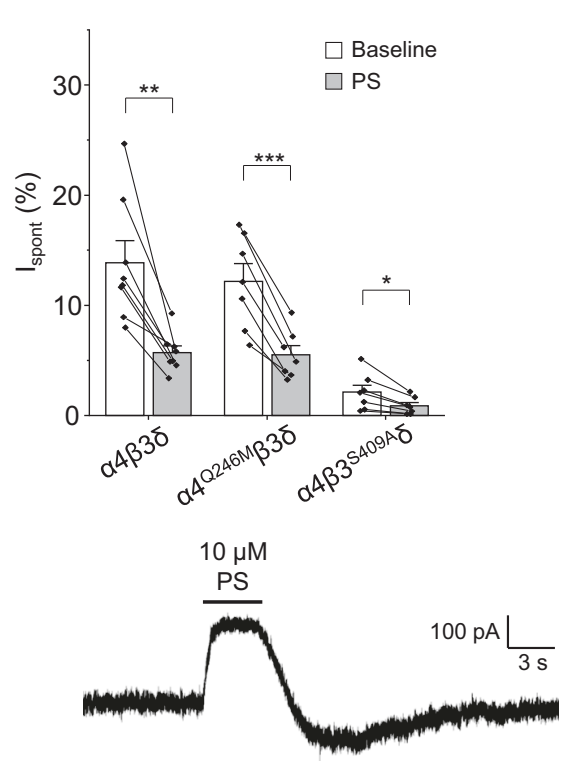

b

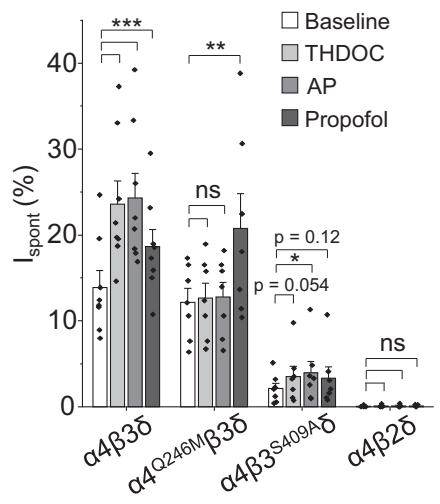

d

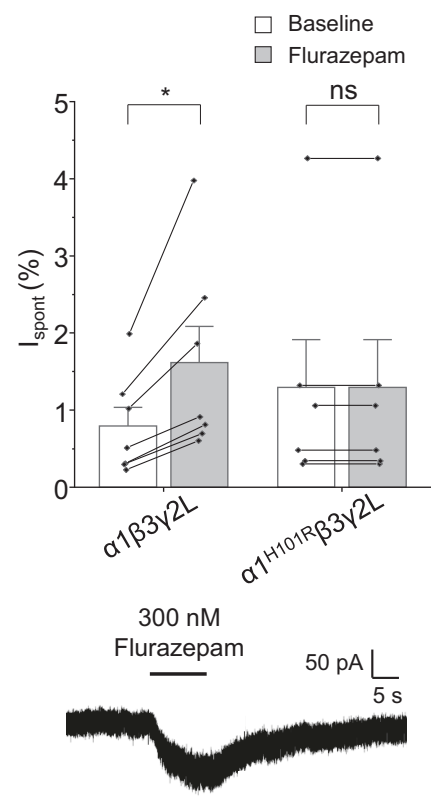

Fig. 6 Allosteric modulators of $\mathbf{G A B A}_{\mathbf{A}}$ Rs regulate spontaneous currents. a Recordings of various receptor isoforms exposed to the positive allosteric modulators THDOC $(100 \mathrm{nM})$, allopregnanolone $(\mathrm{AP}, 100 \mathrm{nM})$ and propofol $(1 \mu \mathrm{M})$. b Modulator-induced changes in holding current $\mathrm{I}_{\mathrm{Mod}}$ were measured, before saturating GABA $(500 \mu \mathrm{M})$ and PTX $(100 \mu \mathrm{M})$ were applied. The $I_{\text {Mod }}$ was added to the $I_{\text {PTX }}$ to calculate $I_{\text {spont }}$ in the presence of the modulators (see Methods). Wild-type $\alpha 4 \beta 3 \delta \mathrm{I}_{\text {spont }}$ was potentiated by THDOC ( $\left.{ }^{\star \star \star} P=4.7 \mathrm{E}-8\right)$, AP $\left({ }^{\star \star \star} P<1.0 \mathrm{E}-9\right)$ and propofol $\left({ }^{\star \star \star} P=0.00029 ; n=8\right)$. The neurosteroid-insensitive $\alpha 4 \mathrm{Q} 246 \mathrm{M} \beta 3 \delta$ was not affected by THDOC $(P=1.0)$ or $\mathrm{AP}(P=0.99)$, but was potentiated by propofol $\left({ }^{\star \star} P=0.0028 ; n=7\right)$. The little-spontaneous $\alpha 4 \beta 3^{5409 A} \delta$ was potentiated by all modulators, but the effect was not statistically significant for some (THDOC: $P=0.054, A P$ : ${ }^{\star} P=0.011$, propofol: $\left.P=0.12 ; n=7\right)$. The non-spontaneous $\alpha 4 \beta 2 \delta$ was not potentiated by any modulator $(P \geq 0.63 ; n=5)$. All comparisons used one-way repeated measures ANOVA with Tukey's post-hoc test. $\mathbf{c}$ Pregnenolone sulfate (PS, $10 \mu \mathrm{M}$ ) reduced spontaneous currents of $\alpha 4 \beta 3 \delta$ ( ${ }^{\star \star} P=0.0023 ; n=8$ ), $\alpha 4 \mathrm{Q} 246 \mathrm{M} \beta 3 \delta\left({ }^{\star \star \star} P=0.00060 ; n=7\right)$ and $\alpha 4 \beta 3^{5409 A} \delta$ receptors ( ${ }^{\star} P=0.011 ; n=7$; two-sided paired $t$-tests). Representative holding current of $\alpha 4 \beta 3 \delta$ during PS application is shown below. $\mathbf{d}$ Flurazepam $(300 \mathrm{nM})$ potentiated spontaneous currents of $\alpha 1 \beta 3 \gamma 2 \mathrm{~L}$ receptors $\left({ }^{\star} P=0.011\right.$; two-sided paired $t$-test; $n=7)$, but not for the benzodiazepine-insensitive $\alpha{ }^{H 101 R} \beta 3 \gamma 2 \mathrm{~L}$ receptor $(P=1.0$; two-sided Wilcoxon signed-rank test; $n=6)$. Representative current of wild-type $\alpha 1 \beta 3 \gamma 2 \mathrm{~L}$ during flurazepam application is shown below. Data are presented as mean values $\pm \mathrm{SEM}$. ${ }^{\star} P<0.05 ;{ }^{\star \star} P<0.01 ;{ }^{\star \star \star} P<0.001 ; \mathrm{ns}$ no significance. Source data are provided as a Source Data file for Fig. 6.

best described by the sum of two exponential components and the respective time constants $(\tau 1, \tau 2)$ were significantly increased by $100 \mathrm{nM}$ THDOC (Fig. 7a-c). Our recordings suggest that more than one channel was often present in each patch (occasional channel stacking), so no closed time analysis was attempted, especially given the paucity of bursts (Fig. 7c). The proportion of channel openings in the short and long open time distributions (A1 and $\mathrm{A} 2$, respectively) suggested that $100 \mathrm{nM}$ THDOC may promote increased openings in $\mathrm{A} 2$ at the expense of those in $\mathrm{A} 1$, although this was noted only as a trend (Fig. 7b).
In summary, both our macroscopic and single-channel currents reveal that allosteric modulation of $\mathrm{GABA}_{\mathrm{A}} \mathrm{R}$ activity occurs in the absence of an orthosteric agonist. As for the potentiation of GABA-gated receptors, the positive modulators we describe here increase the open probability of the GABA channel, shifting the equilibrium of the receptor population, resulting in a greater proportion of receptors in the open conformation at any given time. Consistent with a recent study showing that the benzodiazepine flurazepam enhances spontaneous $\mathrm{GABA}_{\mathrm{A}} \mathrm{R}$ currents by prolonging single-channel openings ${ }^{19}$, our single-channel 
a
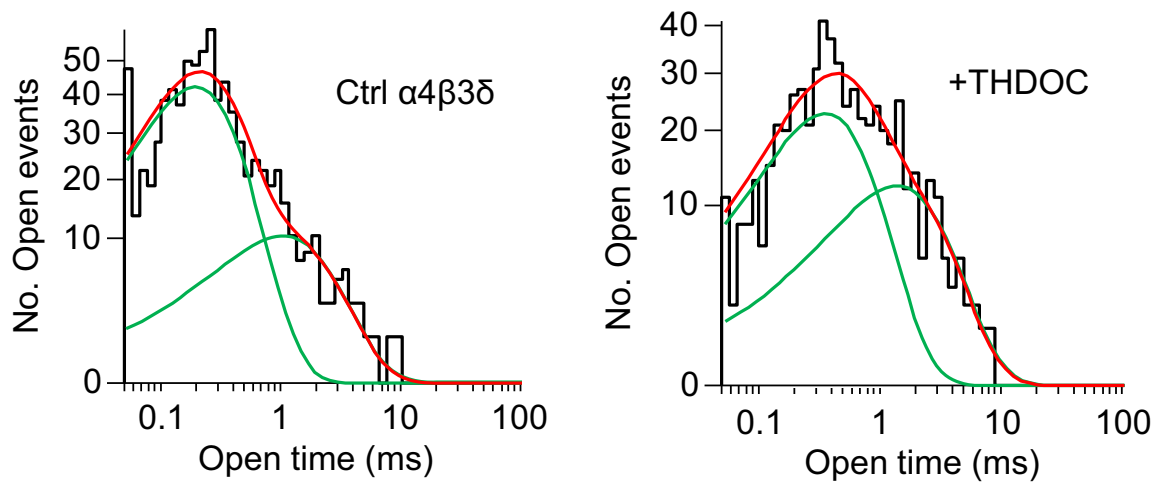

b
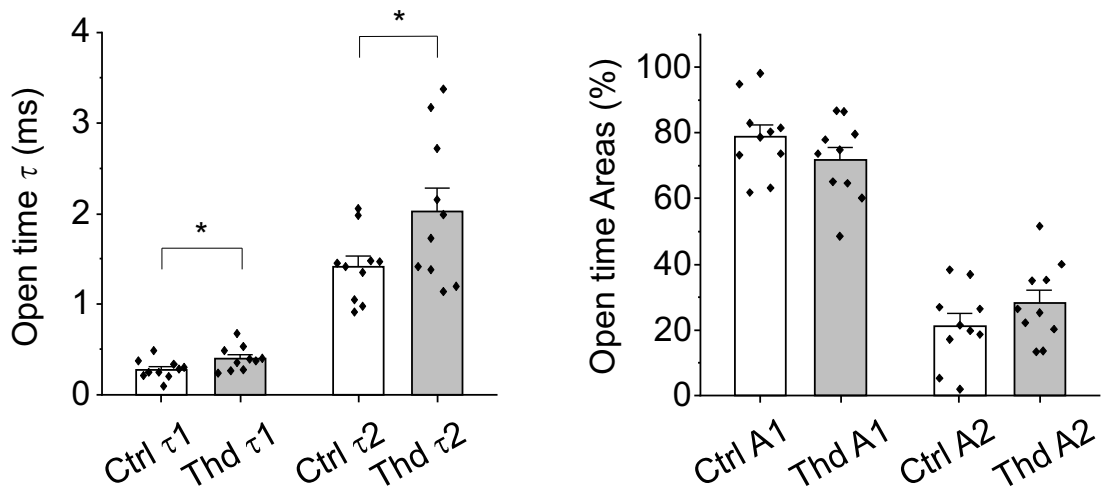

C
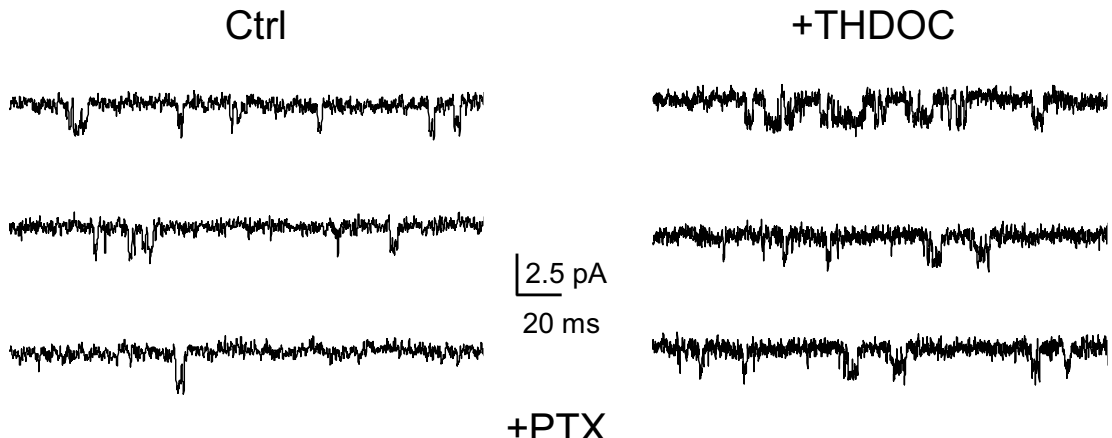

$+\mathrm{PTX}$

Fig. 7 THDOC prolongs the open states for spontaneous $\alpha \mathbf{4} \beta 3 \boldsymbol{3}$ currents. a Open state distributions compiled for spontaneous single-channel currents recorded from $\alpha 4 \beta 3 \delta$ receptors expressed in HEK cells in the absence of GABA, as a control, and in the presence of $100 \mathrm{nM}$ THDOC. Green lines show individual exponential component fits, while red lines depict the overall summed fit from the mixture of exponentials. b Bar graphs for the exponential open time constants $\tau 1$ and $\tau 2$ (left panel) and their respective areas, A1 and A2 (right panel). THDOC increased $\tau 1\left({ }^{\star} P=0.041\right)$ and $\tau 2\left({ }^{\star} P=0.048\right)$ but did not significantly affect the areas $(P=0.30$; two-sided paired $t$-tests; $n=10)$. c Example epochs of spontaneous single-channel recording for $\alpha 4 \beta 3 \delta$ receptors obtained from the same outside-out patch under control conditions (zero GABA, left panel), and in the presence of $100 \mathrm{nM}$ THDOC (right panel) or $100 \mu$ M PTX (lower trace). Calibration bars apply to all traces. Data are presented as mean values \pm SEM. ${ }^{\star} P<0.05$. Source data are provided as a Source Data file for Fig. 7.

recordings indicate that potentiating neurosteroids also prolong spontaneous open channel durations. Therefore, these modulators are likely to impact on tonic inhibition mediated by these activated receptors in vivo, even in the absence of GABA.

Spontaneous $\mathrm{GABA}_{\mathrm{A}} \mathrm{R}$ activity in hippocampal neurons is regulated by $\beta 3$ subunits. To investigate whether $\beta 3$ subunits affect spontaneous $\mathrm{GABA}_{\mathrm{A}} \mathrm{R}$ activity in a physiological context, $\alpha 4, \beta 3$ and $\delta$ subunits were expressed individually or combined in cultured hippocampal neurons. Only neurons transfected with cDNAs for $\alpha 4 \beta 3 \delta$ or $\beta 3$ displayed larger spontaneous currents (determined by applying $100 \mu \mathrm{M}$ PTX to block all $\mathrm{GABA}_{\mathrm{A}} \mathrm{R}$-mediated current and $1 \mu \mathrm{M}$ gabazine to block GABAmediated current) compared to eGFP-expressing control neurons 
a eGFP

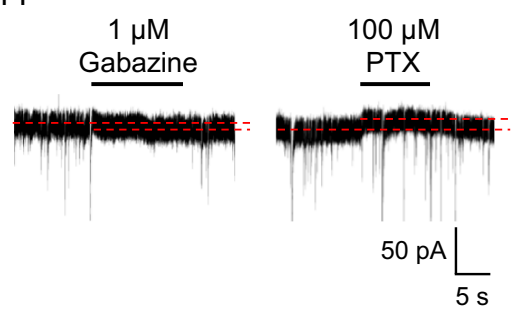

$\beta 3$

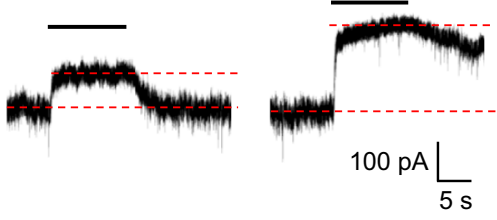

C

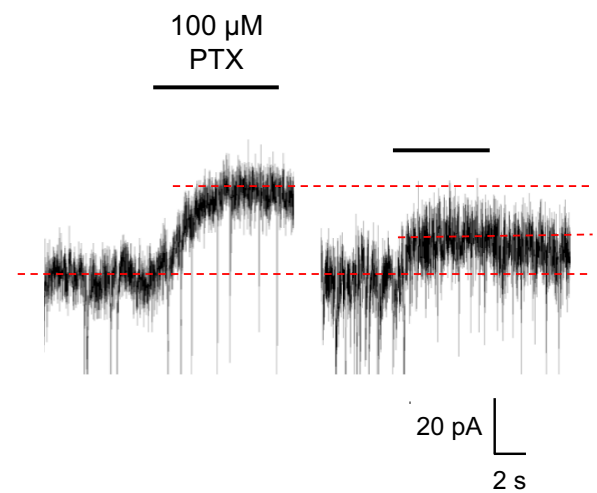

b

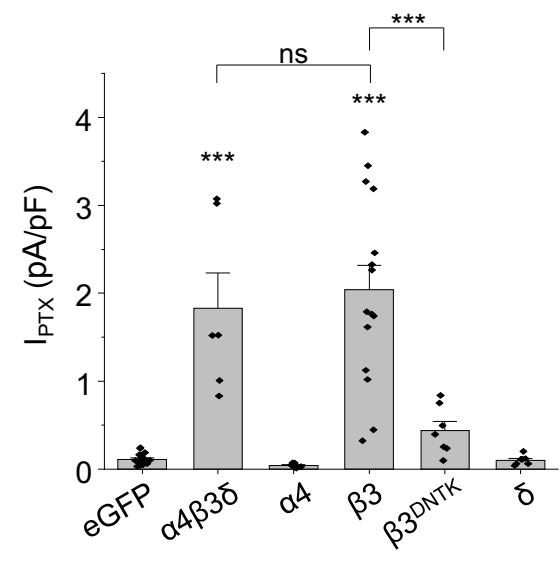

d

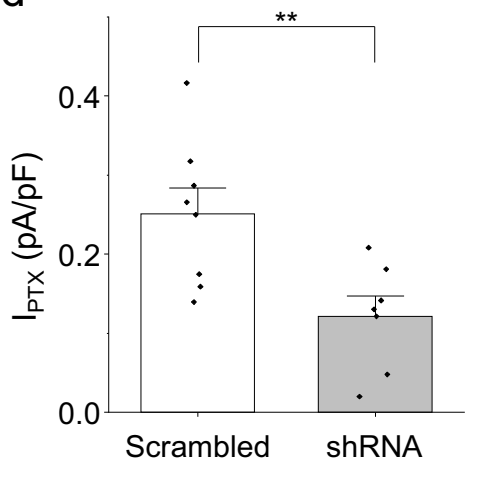

Fig. $8 \beta 3$ subunit controls spontaneous currents in hippocampal neurons. a Recordings from neurons transfected with control eGFP or $\beta 3$ cDNA and exposed to gabazine $(1 \mu \mathrm{M})$ and PTX $(100 \mu \mathrm{M})$. Dashed lines indicate the holding current before and during drug application. Gabazine exhibited a small agonist effect with eGFP-transfected neurons, and partial antagonism at $\beta 3$-transfected neurons. Both gabazine and PTX were applied until the holding current reached a steady state $(\sim 3-5 \mathrm{~s})$. b Neurons transfected with eGFP alone or with $\alpha 4$ or $\delta$ cDNA showed small PTX-sensitive spontaneous current densities. Transfection with either $\alpha 4, \beta 3$ and $\delta$ DNAs together $\left({ }^{\star \star} P=1.3 \mathrm{E}-7\right)$ or $\beta 3$ alone $\left({ }^{\star \star \star} P=4.9 \mathrm{E}-5\right)$ increased spontaneous current densities. Neurons transfected with non-spontaneous $\beta 3^{\text {DNTK }}$ CDNA had spontaneous currents that were not significantly greater than eGFP controls $(P=0.73)$, and substantially less than wild-type $\beta 3$ ( ${ }^{\star} P=0.014$; one-way ANOVA with Tukey's post-hoc test; eGFP: $n=16 ; \alpha 4 \beta 3 \delta: n=5 ; \alpha 4: n=5 ; \beta 3: n=6$; $\beta 3$ DNTK: $n=7 ; \delta: n=6$ ). c Hippocampal neurons were transfected with two shRNAs selective for rat $\beta 3$ knockdown, or with a scrambled control. Recordings of neurons transfected with scrambled control (left) or shRNAs (right) during PTX application are shown. $\mathbf{d}$ PTX-sensitive spontaneous current densities of neurons transfected with the scrambled control were significantly higher than those transfected with shRNAs to knockdown $\beta 3$ subunit expression levels $\left({ }^{\star \star} P=0.0092\right.$; two-sided unpaired $t$-tests; scrambled: $n=8$; shRNA: $n=7$ ). Data are presented as mean values \pm SEM. ${ }^{\star \star} P<0.01 ;{ }^{\star \star \star} P<0.001 ; \mathrm{ns}$ no significance. Source data are provided as a Source Data file for Fig. 8.

(Fig. 8a, b; Supplementary Fig. 4a). Spontaneous currents for $\alpha 4 \beta 3 \delta$ and $\beta 3$ cDNA-transfected neurons were similar in amplitude, suggesting that the level of $\beta 3$ expression is the predominant determinant for the formation of spontaneously active neuronal $\mathrm{GABA}_{\mathrm{A}}$ Rs. The requirement for the $\beta 3$ GKER motif was also evident following expression of the $\beta 3^{\text {DNTK }}$ variant which markedly reduced spontaneous activity below that for wild-type receptors (Fig. 8b; Supplementary Fig. 4a). The $\beta 3$ subunit and GKER motif are therefore important in promoting spontaneous receptor activity in neurons, consistent with our recombinant receptor data.

Spontaneous currents in neurons transfected with only $\beta 3$ cDNA were partly blocked by gabazine $(1 \mu \mathrm{M})$, indicating the formation of heteromeric, rather than homomeric, receptors (Fig. 8a). Preferential expression of heteromers was also supported by larger whole-cell currents in response to GABA $(1 \mu \mathrm{M})$ recorded from $\beta 3$-transfected neurons compared to eGFP controls (Supplementary Fig. 4b). Crucially, the ratio of gabazine to PTX-induced currents was not significantly different between $\beta 3$ and $\alpha 4 \beta 3 \delta$-expressing neurons (Supplementary Fig. 4c) indicating that these neurons most likely express similar relative populations of these receptors and that $\beta 3$ subunit expression is a limiting factor. Importantly, the gabazine/PTX ratio was also comparable with that obtained for the block of spontaneous currents recorded from $\alpha 4 \beta 3 \delta$-expressing HEK cells (Supplementary Fig. 4c), strongly suggesting that the PTX-sensitive currents in neurons must be GABA-independent. We confirmed that spontaneous activity of eGFP- and $\beta 3$-expressing neurons was independent of ambient GABA derived from synaptic release by incubation with the vacuolar $\mathrm{H}^{+}$-ATPase inhibitor concanamycin $\mathrm{A}(0.5 \mu \mathrm{M})$, which reduces vesicular GABA uptake and abolished IPSCs without affecting PTX-sensitive spontaneous currents (Supplementary Fig. 4d, e).

To further explore the importance of $\beta 3$ subunits in promoting spontaneous activity in neurons, selective short hairpin RNAs (shRNAs) were used to reduce $\beta 3$ subunit expression. 
a

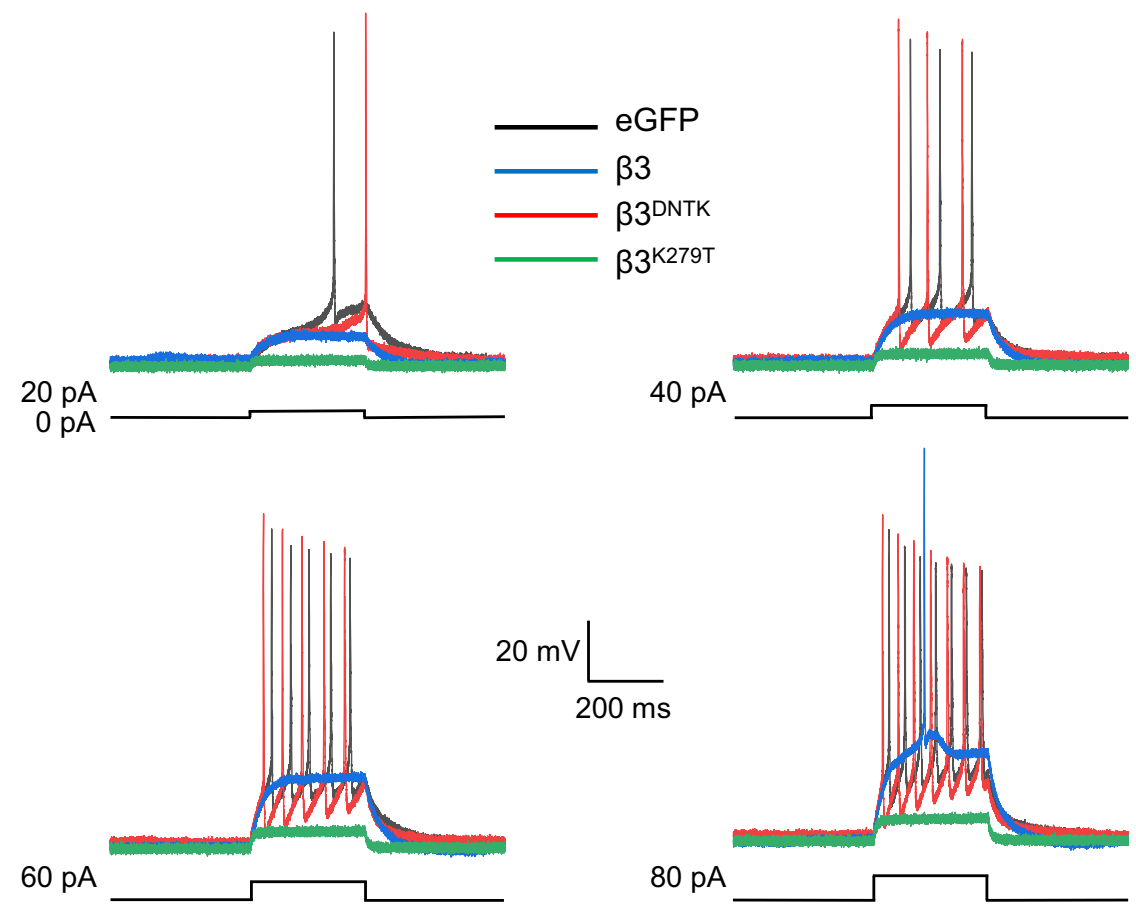

b

C
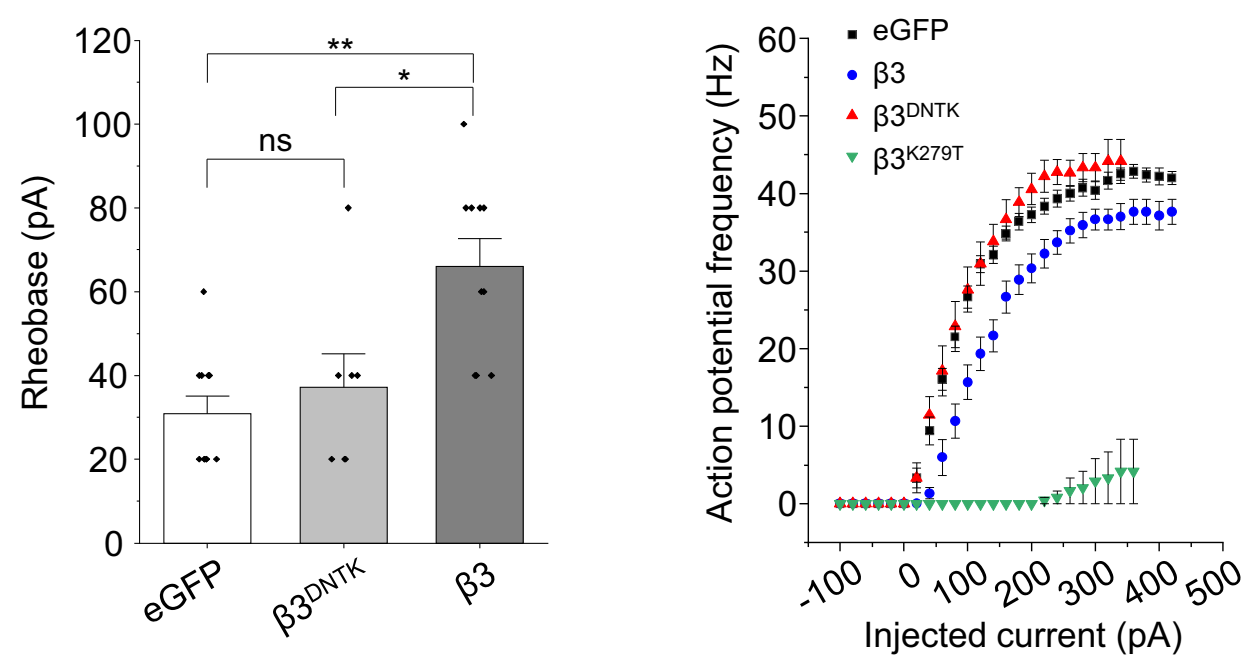

Fig. 9 Spontaneously active $\boldsymbol{\beta 3}$-containing receptors reduce neuronal excitability. a Current clamp recordings from hippocampal neurons expressing eGFP, $\beta 3, \beta 3^{\text {DNTK }}$ or $\beta 3^{K 279 T}$ during injection of depolarising constant current steps of increasing amplitude (20 pA increments). b Rheobase determination for hippocampal neurons transfected with eGFP, $\beta 3$ or $\beta 3^{\text {DNTK }}$ CDNAs. Neurons expressing $\beta 3^{\text {DNTK }}$ showed rheobase values similar to eGFP control $(P=1)$, while $\beta 3$-transfected neurons were less excitable, as demonstrated by higher rheobase values than eGFP ( $\left.{ }^{\star} P=0.0026\right)$ and $\beta 3^{D N T K}$-transfected $\left({ }^{\star} P=0.042\right)$ neurons. Expression of the highly spontaneous $\beta 3^{\mathrm{K} 279 \mathrm{~T}}$ resulted in 7 of 8 neurons unable to evoke action potentials. The one excitable cell had a rheobase of 220 pA (not shown). The input-output curves are shown in c. Kruskal-Wallis with Dunn's post-hoc test were used to compared rheobase values (eGFP: $n=11 ; \beta 3^{\text {DNTK}: ~} n=7 ; \beta 3: n=10 ; \beta 3^{\mathrm{K} 279 T}: n=8$ ). Data are presented as mean values \pm SEM. ${ }^{\star} P<0.05 ;{ }^{\star \star} P<0.01 ; n s$ no significance. Source data are provided as a Source Data file for Fig. 9.

Knockdown of native $\beta 3$ subunits was confirmed with confocal immunofluorescent imaging (Supplementary Fig. 4f) and was accompanied by over $50 \%$ reduction in spontaneous current, compared with neurons transfected with a scrambled shRNA control (Fig. $8 \mathrm{c}, \mathrm{d}$ ). The residual spontaneous currents are likely to reflect incomplete knockdown of the $\beta 3$ subunit.

The impact of $\beta 3$-driven spontaneous currents on neuronal excitability was studied using current clamp recording of action potentials evoked by depolarising current steps. Neurons were transfected with cDNAs for either $\beta 3$, the non-spontaneous $\beta 3^{\mathrm{DNTK}}$ or the highly spontaneous $\beta 3^{\mathrm{K} 279 \mathrm{~T}}$ subunit (Fig. 9). There was neither a shift in the input-output (I-O) relationship for spike firing nor a change in the spike threshold (rheobase) for $\beta 3^{\text {DNTK }}$ neurons compared to eGFP controls. However, for $\beta 3$ expressing neurons, the $\mathrm{I}-\mathrm{O}$ curve was displaced to a higher rheobase. By contrast, $\beta 3^{\mathrm{K} 279 \mathrm{~T}}$-expressing neurons were largely silent, with only $1 / 8$ cells firing in response to a large depolarising current $(>220 \mathrm{pA})$. These results indicate that $\beta 3$ subunits 
a

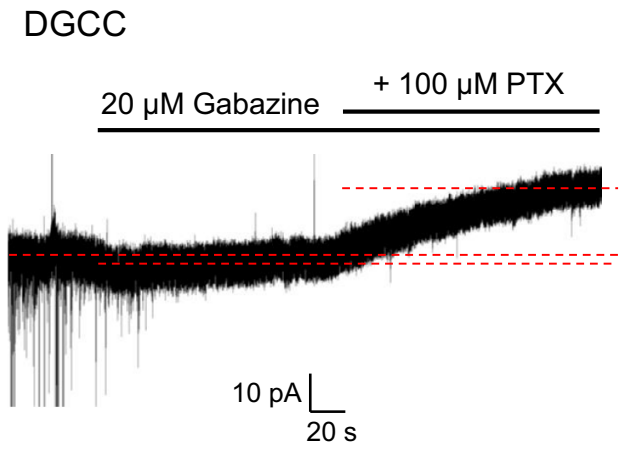

b

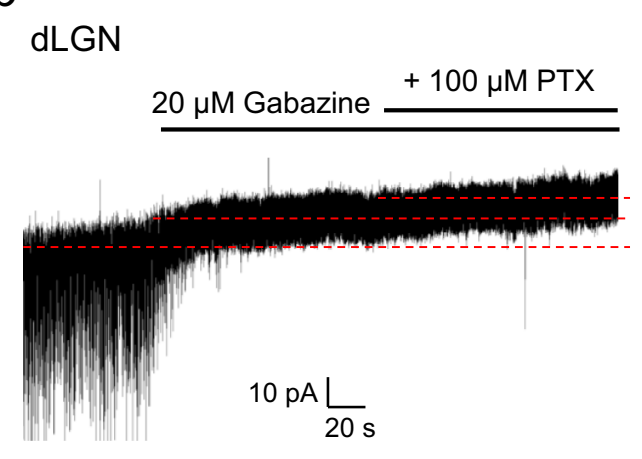

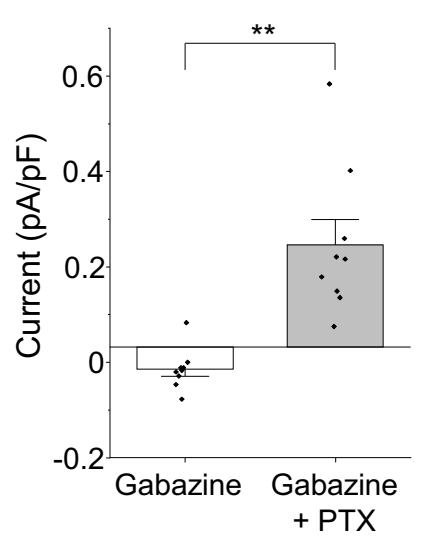

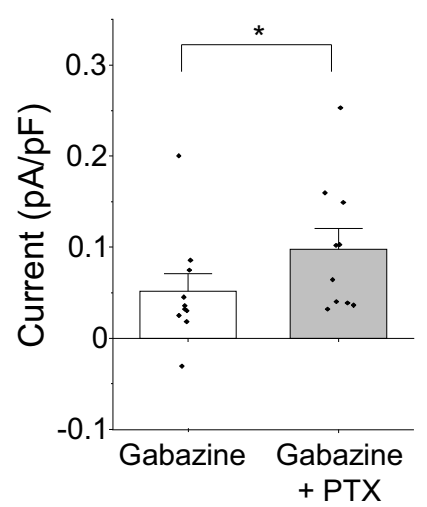

Fig. 10 Tonic inhibition in hippocampal and thalamic neurons is differentially dependent on spontaneous gating of GABA $\mathbf{A}_{\mathbf{A}}$ Rs. a Left: current recording from a dentate gyrus granule cell (DGGC) in an acute hippocampal brain slice showing changes to baseline current when gabazine (20 $\mu M)$ and PTX $(100 \mu \mathrm{M})$ were applied. Right: Holding current density changes during antagonist application ( ${ }^{\star \star} P=0.0018$; two-sided paired $t$-test; $\left.n=9\right)$. b Left: current recording from a relay neuron of the dorsal lateral geniculate nucleus (dLGN) in an acute thalamic brain slice. Right: current density changes during antagonist application ( ${ }^{\star} P=0.032$; two-sided paired $t$-test; $n=10$ ). Data are presented as mean values \pm SEM. ${ }^{\star} P<0.05 ;{ }^{\star \star} P<0.01$. Source data are provided as a Source Data file for Fig. 10.

supporting spontaneously active receptors can substantially reduce the level of neuronal excitability.

Spontaneous activity in different brain regions. After exploring the properties of spontaneously active receptors in heterologous expression systems and cultured neurons ${ }^{12,18}$, it was important to establish whether a similar phenomenon existed in acute brain slices with intact circuitry ${ }^{13}$. We recorded from two regions: rat dentate gyrus granule cells (DGGCs) and dorsal lateral geniculate nucleus (dLGN) thalamic relay neurons, since both express $\delta$ subunit-containing $\mathrm{GABA}_{\mathrm{A}} \mathrm{Rs}^{49-51}$. To pharmacologically dissect the tonic current in these neurons, gabazine $(20 \mu \mathrm{M})$ was used to block the GABA-mediated component of the tonic current, and the residual current, blocked by PTX $(100 \mu \mathrm{M})$, was designated as the spontaneous component. Drugs were applied until steadystate currents were attained. In DGGCs, small increments in holding current were caused by gabazine, consistent with an agonist effect previously reported ${ }^{13}$, followed by a large reduction in holding current with PTX (Fig. 10a). In contrast, tonic currents of thalamic relay neurons were part-inhibited by gabazine, leaving a residual current blocked by PTX (Fig. 10b). We conclude that tonic current in DGGCs is primarily mediated by spontaneous $\mathrm{GABA}_{\mathrm{A}} \mathrm{R}$ activity, consistent with an earlier study ${ }^{13}$, whereas in $\mathrm{dLGN}$ thalamic relay neurons, tonic current is more reliant on GABA-mediated activity.

\section{Discussion}

In this study we have examined a relatively unexplored area of tonic inhibition involving the contribution of spontaneously active $\mathrm{GABA}_{\mathrm{A}}$ Rs. Although this feature of $\mathrm{GABA}_{\mathrm{A}} \mathrm{Rs}$ has been noted, we have little insight into its properties and regulation ${ }^{12-14,17,18}$, including which receptor isoforms are spontaneously active and whether the phosphorylation state of the receptor is crucial ${ }^{18,52,53}$. Here, we demonstrate how spontaneity is reliant upon receptor subunit composition, posttranslational modification, and also the level of allosteric modulation. Furthermore, under physiological conditions, we demonstrate that receptor spontaneity is likely to impact upon neuronal excitability via its contribution towards tonic current.

The $\beta$ subunit is a key assembly component of $\mathrm{GABA}_{\mathrm{A}} \mathrm{Rs}^{27,54}$. Despite the considerable homology between $\beta$ subunits, only $\beta 3$ was identified as being essential for spontaneity. Nevertheless, other subunits are also important, exemplified by $a 4 \beta 3 \delta$ receptors displaying higher levels of spontaneity than $\alpha 1 \beta 3 \gamma 2 \mathrm{~L}$. Furthermore, single subunit exchanges, such as $\alpha 1$ for $\alpha 4$, or $\gamma 2 \mathrm{~L}$ for $\delta$, are sufficient to reduce spontaneous activity. Our molecular studies identified the GKER motif in the $\beta 3$ ECD as a critical factor for the expression of spontaneity. Within a pentamer, this motif is located to the complementary $(-)$ side of the subunit interface and, given its role in $\beta 3$ homo-oligomerisation, is likely to interact with residues on the adjacent subunit's principal face $^{27}$. Structural models predict that GABA binding 'locks' the 
$\beta^{+}-\alpha^{-}$interface into a compact conformation, pulling the subunits closer together to widen the channel pore ${ }^{48}$. Given that the GKER motif is likely to contact residues on adjacent subunits ${ }^{27}$, its presence may strengthen these interactions, facilitating channel opening in the absence of bound agonist. This may also explain the requirement for specific receptor subunit compositions ( $\alpha 4 / 6$ and $\delta$ ) for spontaneity, as GKER interactions at two interfaces may be necessary to lower the activation energy sufficiently to promote spontaneous channel opening. Indeed, expressing $\beta 3$ subunits with half-substituted GKER motifs, $\beta 3^{\mathrm{DN}}$ and $\beta 3^{\mathrm{TK}}$, was sufficient to significantly reduce spontaneous currents in heteromeric receptors, but had no effect on the spontaneous currents of homomeric receptors. Presumably, a halfsubstituted motif may be capable of promoting spontaneity when there are five $\beta^{+}-\beta^{-}$interfaces, but not when only two $\left(\alpha^{+}-\beta^{-}\right.$ and $\left.\delta^{+}-\beta^{-}\right)$exist in heteromers. The importance of nonorthosteric subunit interfaces for modulating receptor activity is highlighted by the activity of benzodiazepines and by novel compounds that target $\alpha^{+}-\beta^{-}$interfaces $44,46,55,56$.

The GKER motif lies within binding loop $\mathrm{F}$ of the $\beta$ subunit ${ }^{5}$. The role of loop F in Cys-loop receptors is still to be fully defined but may involve transducing ligand-binding to channel gating ${ }^{57-59}$. Interestingly, residues within this loop of the $\beta 2$ subunit stabilise the closed state of $\alpha 1 \beta 2 \gamma 2$ receptors, and mutations can modify GABA potency and induce spontaneous gating ${ }^{60}$. The impact of GKER on spontaneous gating and agonist sensitivity, combined with its distance from the GABA binding site, suggests a role in signal transduction. A link between constitutive gating and agonist responsiveness has been previously observed ${ }^{61-63}$, with mutation of the $9^{\prime}$ leucine in the pore-lining M2 region of $\beta 3$ subunits increasing spontaneous activity and agonist potency ${ }^{31}$. The enhanced sensitivity to agonists, linked to constitutive activity, may promote GABA-mediated transmission via extrasynaptic and perisynaptic $\mathrm{GABA}_{\mathrm{A}} \mathrm{Rs}$, which are exposed to only low concentrations of GABA.

Spontaneous tonic currents displayed considerable variability in cultured and ex vivo neurons. Different expression levels of the $\beta 3$ subunit will have a profound impact on spontaneous $G_{A B A} R$ activity and neuronal excitability evidenced by the degree of spontaneity in hippocampal DGGCs, which express high levels of $\beta 3^{49}$. Furthermore, our recombinant receptor study indicates that extrasynaptic-type $\alpha 4 / \delta$-containing receptors generate the largest spontaneous currents, and these receptors are also responsible for the majority of tonic inhibition in DGGCs ${ }^{51}$. Indeed, with physiological ambient GABA levels, almost all the tonic current in the DG is produced by spontaneous receptor activation ${ }^{13}$. The reduced spontaneous activity apparent in thalamic relay neurons is also consistent with reduced $\beta 3$ compared to $\beta 1 / 2$ expression and assembly in their extrasynaptic $\alpha 4 \beta \delta$ receptors ${ }^{49,50}$. This also accords with prior studies suggesting presynaptic GABA release underpins the tonic current in thalamic relay neurons ${ }^{64}$.

Although our use of PTX, a non-subunit-selective inhibitor of $\mathrm{GABA}_{\mathrm{A}} \mathrm{Rs}$, does not unequivocally identify $\beta 3$-containing receptors as being responsible for spontaneous activity, it is highly probable, given our recombinant receptor data and shRNA knockdown studies, that $\beta 3$ subunits dictate spontaneous activity in vivo. We would predict that other areas of the brain exhibiting high expression of $\beta 3$, alongside strong $\alpha 4 / 6$ and $\delta$ subunit expression, should also present tonic currents dependent upon spontaneous receptor activity, e.g. striatal medium spiny neurons possess $\delta$-GABA $\mathrm{A}$-dependent tonic currents ${ }^{65}$ and robustly express $\beta 3$ over $\beta 1 / 2$ subunits ${ }^{49,66}$. Indeed, the importance of $\beta 3$ subunits for tonic inhibition in these neurons was affirmed using conditional $\beta 3$ knockout studies, in which tonic inhibition was severely impaired and neuronal excitability enhanced ${ }^{66}$.
Complementing the role of subunit composition, we also demonstrated that spontaneous activity is subject to receptor modulation by protein kinases, neurosteroids, benzodiazepines and general anaesthetics. Analysing spontaneous single-channel currents indicated that THDOC prolonged the existing open channel states $(\tau 1, \tau 2)$ and did not cause the appearance of new additional exponential components in the dwell-time distribution ${ }^{19}$. This suggests that neurosteroids are probably not inducing new kinetically distinct channel states per se, but instead most likely modulating already activated (spontaneous) channels. The dependence of spontaneity on receptor phosphorylation state was evident by mutating subunit phosphorylation sites, and by its modulation with protein kinases. This accords with previous work showing PKA activation enhances spontaneous currents mediated by $\alpha 4 \beta 3 \delta$ receptors by increasing single-channel opening frequency ${ }^{18}$. In the present study, spontaneous activity depended upon phosphorylation of $\beta 3$ S408 and S409 and only receptors phosphorylated at both serines displayed maximum spontaneous gating. Intriguingly, phosphorylation of either $\$ 408$ or S409 enhances the potentiation by neurosteroids and, reciprocally, neurosteroids promote $\beta 3$ subunit phosphorylation ${ }^{67}$. Phosphorylation of $\beta$ subunits has multiple effects on receptor activity and trafficking and can be affected by various signalling pathways, including G-protein-coupled receptors and receptor tyrosine kinases ${ }^{38,68}$. Changes to spontaneous currents initiated by such signalling pathways would represent novel mechanisms through which network activity can be controlled.

In summary, we have provided a comprehensive overview of the structural determinants and modulatory mechanisms underpinning spontaneous $\mathrm{GABA}_{\mathrm{A}} \mathrm{R}$ activity. Residues within the $\mathrm{ECD}$ (the $\beta 3$ GKER motif), the M2-M3 linker (residue K279) which is important for gating, and the M3-M4 ICD (the established phosphorylation sites $\$ 408,409$ ), all impact on the ability of $\beta 3$ to support spontaneous activity. The inherent plasticity of spontaneous currents allows receptors to act not simply as leak channels, but as a highly regulated signalling pathway to control levels of neuronal activity. We have detected spontaneous currents in both synaptic and extrasynaptic receptor isoforms and spontaneous currents are therefore likely to be found throughout the brain where they could provide varying levels of inhibition. The critical importance of the $\beta 3$ subunit for normal brain function is clear from knockout studies ${ }^{69}$ and multiple mutations of this subunit have been linked with epilepsy ${ }^{70}$. Exerting control over spontaneous activity in disease states may provide a novel therapeutic avenue, particularly by targeting subunit interfaces.

\section{Methods \\ Mutagenesis. Point mutations in $\mathrm{GABA}_{\mathrm{A}} \mathrm{R}$ subunits were generated using Phu- sion polymerase (ThermoFisher) or Q5 polymerase (New England Biolabs) in accord with manufacturers guidance. For generating chimeric subunits, restriction- free cloning was used to exchange cDNA sequences from different $\mathrm{GABA}_{\mathrm{A}} \mathrm{R}$ subunit plasmids. Primers were generated and PCR conditions determined using online resources (https://www.rf-cloning.org). The primer sequences used to gen- erate the mutant subunits are provided in Supplementary Table 2.}

Cell culture and transfection. HEK 293 cells were maintained in Dulbecco's modified Eagle's medium supplemented with $10 \% \mathrm{v} / \mathrm{v}$ heat-inactivated fetal calf serum, 100 units $/ \mathrm{ml}$ penicillin-G and $100 \mu \mathrm{g} / \mathrm{ml}$ streptomycin and incubated at $37^{\circ} \mathrm{C}$ in humidified $95 \%$ air $/ 5 \% \mathrm{CO}_{2}$. All components were obtained from Life Technologies. Cells were maintained within a passage range of P12-35. Dissociated HEK cells were plated onto $22 \mathrm{~mm}$ glass coverslips (VWR) coated in poly-L-lysine (Sigma). Cells were transfected $>1$ h later using a calcium phosphate protocol whereby a transfection solution was prepared consisting of $20 \mu \mathrm{l}$ of $340 \mathrm{mM} \mathrm{CaCl}_{2}$, $24 \mu \mathrm{l}$ of $2 \times \mathrm{HBS}$ ( $50 \mathrm{mM}$ HEPES, $280 \mathrm{mM} \mathrm{NaCl}, 2.8 \mathrm{mM} \mathrm{Na} \mathrm{HPO}_{4}$ ) and $4 \mu \mathrm{g}$ cDNA per coverslip. All cells were transfected with equal amounts of mouse $\mathrm{GABA}_{\mathrm{A}} \mathrm{R}$ subunit $\mathrm{cDNA}$, and with eGFP cDNA for transfections other than those using rat $\delta$ cDNA, which included a super-ecliptic pHluorin at its $\mathrm{N}$-terminus ${ }^{62}$. Cells were recorded from $24-48 \mathrm{~h}$ later. 
Rat hippocampal cultures were prepared from E18 Sprague-Dawley embryos; dissociated cells were plated onto $22 \mathrm{~mm}$ glass coverslips coated with poly-Lornithine (Sigma) in a plating medium consisting of minimum essential media supplemented with $5 \% \mathrm{v} / \mathrm{v}$ heat-inactivated fetal calf serum, $5 \% \mathrm{v} / \mathrm{v}$ heatinactivated horse serum, 10 units $/ \mathrm{ml}$ penicillin-G, $10 \mu \mathrm{g} / \mathrm{ml}$ streptomycin, $2 \mathrm{mM}$ L-glutamine and $20 \mathrm{mM}$ glucose and incubated at $37^{\circ} \mathrm{C}$ in humidified $95 \%$ air $/ 5 \%$ $\mathrm{CO}_{2}$. This media was replaced $2 \mathrm{~h}$ later with neurobasal-A media supplemented with $1 \% \mathrm{v} / \mathrm{v}$ B-27, 50 units $/ \mathrm{ml}$ penicillin-G, $50 \mu \mathrm{g} / \mathrm{ml}$ streptomycin, $0.5 \% \mathrm{v} / \mathrm{v}$ glutamax and $35 \mathrm{mM}$ glucose. These cells were transfected 6-8 days later using either the calcium phosphate protocol described above, or Effectene with a protocol as described by the manufacturer (Qiagen) using a total $0.8 \mu \mathrm{g}$ of cDNA per coverslip. All cells were transfected with equal amounts of $\mathrm{GABA}_{\mathrm{A}} \mathrm{R}$ subunit and eGFP cDNAs. Neurons were used for electrophysiological recording or confocal imaging 5-9 days later.

Brain slice recording. Adolescent male rats (P21-P28) were anaesthetised by inhalation with $5 \%$ isoflurane before dispatch and isolation of the brain in accordance with the United Kingdom Animals (Scientific Procedures) Act 1986. The brain was immersed in an ice-cold slicing solution containing (mM): $85 \mathrm{NaCl}$ $2.5 \mathrm{KCl}, 1.25 \mathrm{NaH}_{2} \mathrm{PO}_{4}, 26 \mathrm{NaHCO}_{3}, 75$ sucrose, $1 \mathrm{CaCl}_{2}, 4 \mathrm{MgCl}_{2}, 25$ glucose and 2 kynurenic acid, $\left(\mathrm{pH} 7.4\right.$ when bubbled with $\left.95 \% \mathrm{O}_{2} / 5 \% \mathrm{CO}_{2}\right)$. Horizontal (hippocampal) and coronal (thalamic) sections (all $350 \mu \mathrm{m}$ thick) were cut using a Leica VT1200S vibratome before transfer to a holding chamber at $37^{\circ} \mathrm{C}$. The solution was slowly exchanged over $1 \mathrm{~h}$ with aCSF containing $(\mathrm{mM}): 125 \mathrm{NaCl}, 2.5$ $\mathrm{KCl}, 1.25 \mathrm{NaH}_{2} \mathrm{PO}_{4}, 26 \mathrm{NaHCO}_{3}, 2 \mathrm{CaCl}_{2}, 1 \mathrm{MgCl}_{2}, 25$ glucose and 2 kynurenic acid ( $\mathrm{pH} 7.4$ when bubbled with $95 \% \mathrm{O}_{2} / 5 \% \mathrm{CO}_{2}$ ) before maintaining the slices at room temperature prior to recording.

Whole-cell patch clamp electrophysiology. For all electrophysiological experiments, cells were visualised using a Nikon Eclipse E600FN microscope. Whole-cell currents were recorded using an Axopatch 200B amplifier and digitised using a Digidata 1322 A (Axon Instruments). Currents were acquired with Clampex ver. 10.2 and analysed with Clampfit ver. 10.7 (Axon Instruments) on a Dell Optiplex $960 \mathrm{M}$ computer. Recordings were sampled at $20 \mathrm{kHz}$ and filtered at $2 \mathrm{kHz}$. All recordings were performed at room temperature $\left(20^{\circ} \mathrm{C}\right)$. Series resistance compensation was $\sim 70 \%$, and cells were rejected if series resistance was too high $(>20$ $\mathrm{M} \Omega$ ) and if the leak current was greater than $250 \mathrm{pA}$. For prolonged recordings, cells were rejected if the series resistance changed $>20 \%$ over the recording time. Drugs were applied using a fast-application Y-tube ${ }^{71}$.

HEK cells were recorded from using borosilicate glass electrodes with resistances $\sim 3-5 \mathrm{M} \Omega$ when filled with an internal solution containing (mM): 1 $\mathrm{MgCl}_{2}, 140 \mathrm{KCl}, 11$ EGTA, $10 \mathrm{HEPES}, 1 \mathrm{CaCl}_{2}, 2 \mathrm{~K}_{2} \mathrm{ATP}, \mathrm{pH}$ 7.2. Osmolarity was $300 \pm 20 \mathrm{mOsm} / \mathrm{L}$, measured using a vapour pressure osmometer (Model 5520, Wescor Inc). For experiments investigating kinase modulation, drugs were added to the internal solution to the required concentrations using stock solutions made up in DMSO, with vehicle controls performed using equivalent DMSO concentrations. Cells were perfused with a modified Kreb's solution containing (mM): $140 \mathrm{NaCl}, 4.7 \mathrm{KCl}, 1.2 \mathrm{MgCl}_{2}, 2.5 \mathrm{CaCl}_{2}, 11$ glucose, 5 HEPES, pH 7.4. Cells were voltage clamped at $-40 \mathrm{mV}$.

Recordings from hippocampal cultures used $\sim 3-5 \mathrm{M} \Omega$ electrodes filled with an internal solution consisting of (mM): $140 \mathrm{CsCl}, 2 \mathrm{NaCl}, 10$ HEPES, 5 EGTA, 2 $\mathrm{MgCl}_{2}, 0.5 \mathrm{CaCl}_{2}, 2 \mathrm{Na}_{2} \mathrm{ATP}, 0.5 \mathrm{Na}_{2} \mathrm{GTP}, 2 \mathrm{QX}-314, \mathrm{pH}$ 7.3. Osmolarity was $300 \pm 20 \mathrm{mOsm} / \mathrm{L}$. Cells were perfused in the same Kreb's solution described above, except for the addition of $2 \mathrm{mM}$ kynurenic acid. Cells were voltage clamped at $-60 \mathrm{mV}$. For current clamp, cells were recorded using an internal electrode solution consisting of $(\mathrm{mM}): 137$ potassium gluconate, $3 \mathrm{KCl}, 10 \mathrm{HEPES}, 5 \mathrm{EGTA}$, $0.5 \mathrm{CaCl}_{2}, 2 \mathrm{MgCl}_{2}, 2 \mathrm{Na}_{2} \mathrm{ATP}$ and $0.5 \mathrm{Na}_{2} \mathrm{GTP}, \mathrm{pH}$ 7.3. Osmolarity was $300 \pm 20 \mathrm{mOsm} / \mathrm{L}$. The external solution was as described for voltage-clamp experiments and the calculated junction potential was $\sim 15 \mathrm{mV}$. Current was injected to hold cells at $-70 \mathrm{mV}$ if required. For slice recordings, slices were perfused in the aCSF described above, and the internal solution was the same as that used for cultured neuronal voltage-clamp recordings.

Single-channel recording and analysis. Single spontaneous GABA channel currents were recorded from outside-out patches of HEK cells expressing $a 4 \beta 3 \delta$ $\mathrm{GABA}_{\mathrm{A}} \mathrm{Rs}$ and eGFP at a holding potential of $-70 \mathrm{mV}$. To limit ion channel density in individual patches, HEK cells were transfected with $5 \mathrm{ng} \alpha 4, \beta 3, \delta$ and eGFP cDNAs. Resulting spontaneous single-channel currents were digitised at a sampling rate of $20 \mathrm{kHz}$ and filtered at $5 \mathrm{kHz}$ with a 4-pole Bessel filter $(24 \mathrm{~dB}$ per octave). A fixed time resolution of $80 \mu \mathrm{s}$ was used as a preset. Recordings were undertaken using thick-walled borosilicate patch pipettes $(6-10 \mathrm{M} \Omega$ ) filled with a solution containing (mM): $145 \mathrm{CsCl}, 2.5 \mathrm{NaCl}, 10$ HEPES, 1 EGTA, $4 \mathrm{MgATP}, \mathrm{pH}$ 7.3. Osmolarity was $300 \pm 20 \mathrm{mOsm} / \mathrm{L}$. Cells were perfused with an external solution consisting of (mM): $145 \mathrm{NaCl}, 2.5 \mathrm{KCl}, 1 \mathrm{CaCl}_{2}, 1 \mathrm{MgCl}_{2}, 10$ HEPES, 10 glucose, $\mathrm{pH}$ 7.3. Prior control recordings were obtained using untransfected HEK cells to identify endogenous channel currents. Rarely, long open events characteristically devoid of brief closures were observed in some of these recordings, but they are easily distinguishable from the spontaneous $\mathrm{GABA}_{\mathrm{A}} \mathrm{R}$ channel currents.
Channel currents were digitally low pass filtered at $1-2 \mathrm{kHz}$ prior to analysis. Single-channel conductance (typically 27-30 pS) was calculated from the mean unitary channel current and the difference between the patch holding potential and GABA current reversal potential. Channel dwell states were identified using a threshold cursor method. This state transition detection method for open and shut events was used to assemble an idealised record of the digitised data. Open times affected by channel stacking were not included in the analyses and subconductance states were also rare and excluded from the analysis.

The analysis of the dwell times for single-channel currents was performed by fitting a mixture of exponential components to the open time distributions. These defined the mean open times and their relative proportions (area of the components) based on using a Levenberg-Marquardt non-linear least-squares routine (WinEDR ver 3.8.7, courtesy of J Dempster, University of Strathclyde).

Quantification of spontaneous activity in HEK cells. Spontaneous activity in HEK cells was quantified by applying a saturating concentration of agonist (500 $\mu \mathrm{M}$ GABA unless otherwise stated) to elicit a maximal whole-cell current $\left(\mathrm{I}_{\mathrm{Max}}\right)$. Once the bath solution was exchanged and the current had fully returned to baseline (30-60 s; data were excluded if the baseline current deviated by more than $20 \%$ from its pre-application level), a saturating concentration of PTX $(100 \mu \mathrm{M})$ was then applied until steady state was reached (3-5s) and the current recorded $\left(\mathrm{I}_{\mathrm{PTX}}\right)$. Spontaneous currents $\left(\mathrm{I}_{\text {spont }}\right)$ were quantified as a percentage of total current, as described by Eq. (1):

$\mathrm{I}_{\text {spont }}(\%)=\left[\mathrm{I}_{\mathrm{PTX}} /\left(\mathrm{I}_{\mathrm{PTX}}+\mathrm{I}_{\text {Max }}\right)\right] \times 100$.

For assessment of the efficacy of allosteric modulators on spontaneous activity, compounds were briefly applied ( $3-5 \mathrm{~s})$ to achieve steady-state currents $\left(\mathrm{I}_{\mathrm{Mod}}\right)$. Once the current had returned to pre-application baseline, saturating GABA and PTX concentrations were then applied. The $\mathrm{I}_{\text {Mod }}$ was summed with $\mathrm{I}_{\mathrm{PTX}}$ (or subtracted for inhibitory modulators) and the $\mathrm{I}_{\text {spont }}$ calculated, as described by Eq. (2):

$\mathrm{I}_{\text {spont }}(\%)=\left[\left(\mathrm{I}_{\text {PTX }}+\mathrm{I}_{\text {Mod }}\right) /\left(\mathrm{I}_{\text {PTX }}+\mathrm{I}_{\text {Max }}\right)\right] \times 100 \ldots$

Concentration-response curves and fitting. Increasing concentrations of GABA were applied to HEK cells transiently expressing $\mathrm{GABA}_{\mathrm{A}} \mathrm{Rs}$ to generate currents. These data were plotted and fitted using a non-linear least-squares method with the Hill equation, expressed in Eq. (3):

$$
\mathrm{y}=\left(\mathrm{y}_{\max } \cdot \mathrm{A}^{\mathrm{n}}\right) /\left(\mathrm{EC}_{50}{ }^{\mathrm{n}}+\mathrm{A}^{\mathrm{n}}\right)
$$

Where $\mathrm{A}, \mathrm{y}_{\max }, \mathrm{EC}_{50}$ and $\mathrm{n}$ represent the GABA concentration, the maximum GABA current, the GABA EC 50 , and the Hill coefficient, respectively. All data were normalised to the fitted maximum response.

shRNA and immunocytochemistry. For short hairpin RNA (shRNA)-mediated knockdown (silencing) of native $\beta 3$ subunits in cultured hippocampal neurons, we used co-transfection of two pGIPZ-based constructs (Open Biosystems V2LMM_62992: TTTAAGAAATATGTGTCGG and V2LMM_65176:

TTCATTGTGAACATCCATC) that selectively target rat $\beta 3$. Control neurons were transfected with a pGIPZ construct containing a scrambled shRNA sequence (TCTCGCTTGGGCGAGAGTAAG). pGIPZ constructs also encoded for GFP to allow transfected cell identification.

Seven days after transfection with shRNA constructs, neurons were washed with ice-cold PBS and fixed with paraformaldehyde (4\% PFA/4\% sucrose/ PBS pH 7) for 5 min before extensive washing in PBS. Cells were then permeabilised using Triton $\mathrm{X}-100(0.1 \%)$ for $5 \mathrm{~min}$ and then washed. Cells were incubated in a blocking solution (10\% goat serum) for $30 \mathrm{~min}$ before brief washing and subsequent incubation for $1 \mathrm{~h}$ in $3 \%$ goat serum with a mouse anti- $\beta 3$ primary antibody (NeuroMab, 1:500). Cells were then washed and incubated with a goat anti-mouse secondary antibody conjugated to Alexa Fluor-555 (1:500) for $1 \mathrm{~h}$. After washing, coverslips were mounted on slides with Prolong Glass mounting medium (ThermoFisher Scientific) for confocal imaging.

Cells from at least three different preparations were identified through expression of GFP and were imaged using a Zeiss 510 confocal microscope with a $\times 40$ oil objective (1.4 NA). Images were digitally captured using Zeiss LSM software (ver. 4.2) with excitation at $488 \mathrm{~nm}$ for GFP and $555 \mathrm{~nm}$ for Alexa Fluor-555.

For each neuron, sections from multiple (2-4) proximal dendrites were imaged. For quantification of neuronal $\beta 3$ labelling, ImageJ (ver. 1.52p) was used to determine the mean fluorescence intensity of each dendrite. The average fluorescence intensity per cell was then determined and normalised to the average intensity of all control cells for that preparation.

Generation of homology models. To build a homology model of the murine $\alpha 4 \beta 3 \delta \mathrm{GABA}_{\mathrm{A}} \mathrm{R}$ based on the structure of human $\alpha 1 \beta 3 \gamma 2$ (PDB template: 6153), we created an alignment file, for use by Modeller ver. 9.19, in a pentameric format. 
This required optimal alignments of murine $\alpha 4$ versus human $\alpha 1$, murine $\beta 3$ versus human $\beta 3$, and murine $\delta$ versus human $\gamma 2$, using the EMBL-EBI multiple sequence alignment webtool ClustalW2.

Aligning all murine and human $\mathrm{GABA}_{\mathrm{A}} \mathrm{R} \alpha(1-6)$ subunits revealed the expected high degree of sequence homology (Supplementary Table 3). Template (human a1) from PDB 6I53, is shown highlighted in yellow with corresponding primary sequence for murine $\alpha 4$ shown in green highlight. The intracellular region between M3 and M4 that is not resolved in 6153 (red highlight) was excluded in the Modeller alignment file. A similar approach was adopted for aligning murine and human $\mathrm{GABA}_{\mathrm{A}} \mathrm{R} \beta(1-3)$ subunits. Murine and human $\beta 3$ primary sequences are identical in the regions included in the model (Supplementary Table 4). The most difficult alignment involves that for murine $\delta$ and human $\gamma 2$. We therefore aligned all $\mathrm{GABA}_{\mathrm{A}} \mathrm{R}$ non $\alpha$, non $\beta$ subunits that could fill the fifth position in the $\alpha \beta \mathrm{X}$ heteropentamer, notably: $\gamma 1-3$ (GBRG1-3), $\delta$ (GBRD), $\varepsilon$ (GBRE), $\theta$ (GBRT), $\pi$ (GBRP). This approach provided confidence in the alignments of murine $\delta$ and human $\gamma 2$ for the regions included in the model (Supplementary Table 5). Using all three alignments, a pentameric alignment file for Modeller 9.19 was constructed and used to generate 50 homology models of the $\alpha 4 \beta 3 \delta \mathrm{GABA}_{\mathrm{A}} \mathrm{R}$.

The model quality estimation webtool for membrane proteins, QMEANBrane (http://swissmodel.expasy.org/qmean/), was used to rank all 50 models to obtain the most appropriate structures, which were subsequently processed in SCRWL $4^{72}$ to optimise side-chain configurations. Further model optimisation was performed using MOLProbity (http://molprobity.biochem.duke.edu/) where Asn/Gln/His residues were flipped if clear evidence was provided for protonation. The $\alpha 4 \beta 3 \delta \mathrm{GABA}_{\mathrm{A}} \mathrm{R}$ homology model was then structure minimised in Chimera before final runs through MOLProbity once more, where protein geometry scores showed successful iterative model optimisation leading to the final homology model. All structural images were visualised and rendered using the molecular graphics systems, PyMOL (Schrodinger) and UCSF Chimera.

Statistical analysis and reproducibility. Data are represented as the mean \pm standard error of the mean (SEM). Individual data points are included within figures. Data were analysed and statistical tests performed using Origin 2019 (OriginLab). All datasets were tested for normality using the Kolmogorov-Smirnov test with Lilliefors correction. If data were normally distributed, two-sided unpaired $t$-tests, paired $t$-tests and ANOVA with Tukey's post-hoc tests were used as indicated. For non-Gaussian distributed data, two-sided Mann-Whitney, paired samples Wilcoxon and Kruskal-Wallis with Dunn's post-hoc tests were used. A $P$ value of $<0.05$ was set as the level of significance and denoted by $*$. When $P<0.01$ or $P<0.001$, this is represented by $* *$ and $* * *$, respectively. The $\mathrm{n}$ numbers in the figure legends signify how many times each experiment was repeated independently to ensure reproducible results.

Reporting summary. Further information on experimental design is available in the Nature Research Reporting Summary linked to this paper.

\section{Data availability}

The datasets generated and analysed during this study are included in this published article and in the associated supplementary information files. Any other data associated with this paper are available from the corresponding author upon reasonable request. Source data are provided with this paper.

Received: 19 May 2020; Accepted: 24 August 2021;

Published online: 15 September 2021

\section{References}

1. Sigel, E. \& Steinmann, M. E. Structure, function, and modulation of $\mathrm{GABA}_{\mathrm{A}}$ receptors. J. Biol. Chem. 287, 40224-40231 (2012).

2. Farrant, M. \& Nusser, Z. Variations on an inhibitory theme: phasic and tonic activation of $\mathrm{GABA}_{\mathrm{A}}$ receptors. Nat. Rev. Neurosci. 6, 215-229 (2005).

3. Olsen, R. W. \& Sieghart, W. GABA A receptors: subtypes provide diversity of function and pharmacology. Neuropharmacology 56, 141-148 (2009).

4. Baumann, S. W., Baur, R. \& Sigel, E. Forced subunit assembly in $\alpha 1 \beta 2 \gamma 2$ $\mathrm{GABA}_{\mathrm{A}}$ receptors. Insight into the absolute arrangement. J. Biol. Chem. 277, 46020-46025 (2002).

5. Laverty, D. et al. Cryo-EM structure of the human $\alpha 1 \beta 3 \gamma 2 \mathrm{GABA}_{\mathrm{A}}$ receptor in a lipid bilayer. Nature 565, 516-520 (2019).

6. Mody, I. Distinguishing between $\mathrm{GABA}_{\mathrm{A}}$ receptors responsible for tonic and phasic conductances. Neurochem. Res. 26, 907-913 (2001).

7. Caraiscos, V. B. et al. Tonic inhibition in mouse hippocampal CA1 pyramidal neurons is mediated by a5 subunit-containing $\gamma$-aminobutyric acid type A receptors. Proc. Natl Acad. Sci. USA 101, 3662-3667 (2004).
8. Ali, A. B. \& Thomson, A. M. Synaptic a5 subunit-containing GABA $_{A}$ receptors mediate IPSPs elicited by dendrite-preferring cells in rat neocortex. Cereb. Cortex 18, 1260-1271 (2008).

9. Brickley, S. G., Cull-Candy, S. G. \& Farrant, M. Development of a tonic form of synaptic inhibition in rat cerebellar granule cells resulting from persistent activation of GABA A receptors. J. Physiol. 497, 753-759 (1996).

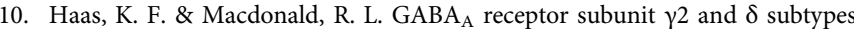
confer unique kinetic properties on recombinant $\mathrm{GABA}_{\mathrm{A}}$ receptor currents in mouse fibroblasts. J. Physiol. 514, 27-45 (1999).

11. Birnir, B., Everitt, A. B., Lim, M. S. \& Gage, P. W. Spontaneously opening $\mathrm{GABA}_{\mathrm{A}}$ channels in CA1 pyramidal neurones of rat hippocampus. J. Membr. Biol. 174, 21-29 (2000).

12. McCartney, M. R., Deeb, T. Z., Henderson, T. N. \& Hales, T. G. Tonically active $\mathrm{GABA}_{\mathrm{A}}$ receptors in hippocampal pyramidal neurons exhibit constitutive GABA-independent gating. Mol. Pharmacol. 71, 539-548 (2007).

13. Wlodarczyk, A. I. et al. GABA-independent $\mathrm{GABA}_{\mathrm{A}}$ receptor openings maintain tonic currents. J. Neurosci. 33, 3905-3914 (2013).

14. Wooltorton, J. R., Moss, S. J. \& Smart, T. G. Pharmacological and physiological characterization of murine homomeric $\beta 3 \mathrm{GABA}_{\mathrm{A}}$ receptors. Eur. J. Neurosci. 9, 2225-2235 (1997).

15. Krishek, B. J., Moss, S. J. \& Smart, T. G. Homomeric $\beta 1 \gamma$-aminobutyric acid A receptor-ion channels: evaluation of pharmacological and physiological properties. Mol. Pharmacol. 49, 494-504 (1996).

16. Lindquist, C. E., Dalziel, J. E., Cromer, B. A. \& Birnir, B. Penicillin blocks human $\alpha 1 \beta 1$ and $\alpha 1 \beta 1 \gamma 2 S \mathrm{GABA}_{\mathrm{A}}$ channels that open spontaneously. Eur. J. Pharmacol. 496, 23-32 (2004).

17. Neelands, T. R., Fisher, J. L., Bianchi, M. \& Macdonald, R. L. Spontaneous and $\gamma$-aminobutyric acid (GABA)-activated $\mathrm{GABA}_{\mathrm{A}}$ receptor channels formed by $\varepsilon$ subunit-containing isoforms. Mol. Pharmacol. 55, 168-178 (1999).

18. Tang, X., Hernandez, C. C. \& Macdonald, R. L. Modulation of spontaneous and GABA-evoked tonic $\alpha 4 \beta 3 \delta$ and $\alpha 4 \beta 3 \gamma 2 \mathrm{~L} \mathrm{GABA}_{\mathrm{A}}$ receptor currents by protein kinase A. J. Neurophysiol. 103, 1007-1019 (2010).

19. Jatczak-Sliwa, M. et al. Distinct modulation of spontaneous and GABAevoked gating by flurazepam shapes cross-talk between agonist-free and liganded $\mathrm{GABA}_{\mathrm{A}}$ receptor activity. Front. Cell. Neurosci. 12, 237 (2018).

20. O'Neill, N. \& Sylantyev, S. Spontaneously opening $\mathrm{GABA}_{\mathrm{A}}$ receptors play a significant role in neuronal signal filtering and integration. Cell Death Dis. 9, 813 (2018).

21. Mitchell, S. J. \& Silver, R. A. Shunting inhibition modulates neuronal gain during synaptic excitation. Neuron 38, 433-445 (2003).

22. Lee, V. \& Maguire, J. The impact of tonic $\mathrm{GABA}_{\mathrm{A}}$ receptor-mediated inhibition on neuronal excitability varies across brain region and cell type. Front. Neural Circuits 8, https://doi.org/10.3389/fncir.2014.00003 (2014).

23. Silver, R. A. Neuronal arithmetic. Nat. Rev. Neurosci. 11, 474-489 (2010).

24. Mortensen, M., Ebert, B., Wafford, K. \& Smart, T. G. Distinct activities of GABA agonists at synaptic- and extrasynaptic-type $\mathrm{GABA}_{\mathrm{A}}$ receptors. J. Physiol. 588, 1251-1268 (2010).

25. Storustovu, S. I. \& Ebert, B. Pharmacological characterization of agonists at $\delta$ containing $\mathrm{GABA}_{\mathrm{A}}$ receptors: Functional selectivity for extrasynaptic receptors is dependent on the absence of $\gamma 2$. J. Pharmacol. Exp. Ther. 316, 1351-1359 (2006).

26. Jensen, M. L. et al. A study of subunit selectivity, mechanism and site of action of the delta selective compound 2 (DS2) at human recombinant and rodent native $\mathrm{GABA}_{\mathrm{A}}$ receptors. Br. J. Pharmacol. 168, 1118-1132 (2013).

27. Taylor, P. M. et al. Identification of amino acid residues within $\mathrm{GABA}_{\mathrm{A}}$ receptor $\beta$ subunits that mediate both homomeric and heteromeric receptor expression. J. Neurosci. 19, 6360-6371 (1999).

28. Eaton, M. M. et al. $\gamma$-aminobutyric acid type A $\alpha 4, \beta 2$, and $\delta$ subunits assemble to produce more than one functionally distinct receptor type. $\mathrm{Mol}$. Pharmacol. 86, 647-656 (2014)

29. Wongsamitkul, N., Baur, R. \& Sigel, E. Toward understanding functional properties and subunit arrangement of $\alpha 4 \beta 2 \delta \gamma$-aminobutyric acid, type $A$ $\left(\mathrm{GABA}_{\mathrm{A}}\right)$ receptors. J. Biol. Chem. 291, 18474-18483 (2016).

30. Barrera, N. P. et al. Atomic force microscopy reveals the stoichiometry and subunit arrangement of the $\alpha 4 \beta 3 \delta \mathrm{GABA}_{\mathrm{A}}$ receptor. Mol. Pharmacol. 73, 960-967 (2008)

31. Patel, B., Mortensen, M. \& Smart, T. G. Stoichiometry of $\delta$ subunit containing $\mathrm{GABA}_{\mathrm{A}}$ receptors. Br. J. Pharmacol. 171, 985-994 (2014).

32. Wieland, H. A., Luddens, H. \& Seeburg, P. H. A single histidine in $G_{A B A}$ receptors is essential for benzodiazepine agonist binding. J. Biol. Chem. 267, 1426-1429 (1992)

33. Akk, G., Shin, D. J., Germann, A. L. \& Steinbach, J. H. GABA type A receptor activation in the allosteric coagonist model framework: relationship between EC $_{50}$ and basal activity. Mol. Pharmacol. 93, 90-100 (2018).

34. Fisher, J. L. A lysine residue in the $\beta 3$ subunit contributes to the regulation of $\mathrm{GABA}_{\mathrm{A}}$ receptor activity by voltage. Mol. Cell. Neurosci. 20, 683-694 (2002).

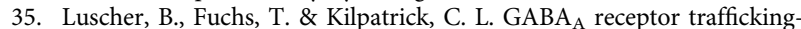
mediated plasticity of inhibitory synapses. Neuron 70, 385-409 (2011) 
36. McDonald, B. J. et al. Adjacent phosphorylation sites on $\mathrm{GABA}_{\mathrm{A}}$ receptor $\beta$ subunits determine regulation by cAMP-dependent protein kinase. Nat. Neurosci. 1, 23-28 (1998).

37. Brandon, N. J. et al. $\mathrm{GABA}_{\mathrm{A}}$ receptor phosphorylation and functional modulation in cortical neurons by a protein kinase C-dependent pathway. $J$. Biol. Chem. 275, 38856-38862 (2000).

38. Nakamura, Y., Darnieder, L. M., Deeb, T. Z. \& Moss, S. J. Regulation of $\mathrm{GABA}_{\mathrm{A}}$ Rs by phosphorylation. Adv. Pharmacol. 72, 97-146 (2015).

39. McDonald, B. J. \& Moss, S. J. Conserved phosphorylation of the intracellular domains of $\mathrm{GABA}_{\mathrm{A}}$ receptor $\beta 2$ and $\beta 3$ subunits by cAMP-dependent protein kinase, cGMP-dependent protein kinase, protein kinase $\mathrm{C}$ and $\mathrm{Ca}^{2+}$ / calmodulin type II-dependent protein kinase. Neuropharmacology 36 1377-1385 (1997).

40. Houston, C. M., Lee, H. H., Hosie, A. M., Moss, S. J. \& Smart, T. G. Identification of the sites for CaMK-II-dependent phosphorylation of $\mathrm{GABA}_{\mathrm{A}}$ receptors. J. Biol. Chem. 282, 17855-17865 (2007).

41. Houston, C. M. \& Smart, T. G. CaMK-II modulation of $\mathrm{GABA}_{\mathrm{A}}$ receptors expressed in HEK293, NG108-15 and rat cerebellar granule neurons. Eur. J. Neurosci. 24, 2504-2514 (2006).

42. Carver, C. M. \& Reddy, D. S. Neurosteroid interactions with synaptic and extrasynaptic $\mathrm{GABA}_{\mathrm{A}}$ receptors: regulation of subunit plasticity, phasic and tonic inhibition, and neuronal network excitability. Psychopharmacology 230, 151-188 (2013).

43. Hosie, A. M., Wilkins, M. E., da Silva, H. M. \& Smart, T. G. Endogenous neurosteroids regulate $\mathrm{GABA}_{\mathrm{A}}$ receptors through two discrete transmembrane sites. Nature 444, 486-489 (2006).

44. Laverty, D. et al. Crystal structures of a $\mathrm{GABA}_{\mathrm{A}}$-receptor chimera reveal new endogenous neurosteroid-binding sites. Nat. Struct. Mol. Biol. 24, 977-985 (2017).

45. Seljeset, S., Bright, D. P., Thomas, P. \& Smart, T. G. Probing GABA $\mathrm{A}$ receptors with inhibitory neurosteroids. Neuropharmacology 136, 23-36 (2018).

46. Olsen, R. W. GABA ${ }_{\mathrm{A}}$ receptor: positive and negative allosteric modulators. Neuropharmacology 136, 10-22 (2018).

47. Sigel, E. \& Ernst, M. The benzodiazepine binding sites of $\mathrm{GABA}_{\mathrm{A}}$ receptors. Trends Pharmacol. Sci. 39, 659-671 (2018).

48. Masiulis, S. et al. GABA A receptor signalling mechanisms revealed by structural pharmacology. Nature 565, 454-459 (2019).

49. Pirker, S., Schwarzer, C., Wieselthaler, A., Sieghart, W. \& Sperk, G. GABA receptors: immunocytochemical distribution of 13 subunits in the adult rat brain. Neuroscience 101, 815-850 (2000).

50. Cope, D. W., Hughes, S. W. \& Crunelli, V. GABA receptor-mediated tonic inhibition in thalamic neurons. J. Neurosci. 25, 11553-11563 (2005).

51. Stell, B. M., Brickley, S. G., Tang, C. Y., Farrant, M. \& Mody, I. Neuroactive steroids reduce neuronal excitability by selectively enhancing tonic inhibition mediated by $\delta$ subunit-containing $\mathrm{GABA}_{\mathrm{A}}$ receptors. Proc. Natl Acad. Sci. USA 100, 14439-14444 (2003).

52. Hadley, S. H. \& Amin, J. Rat $\alpha 6 \beta 2 \delta \mathrm{GABA}_{\mathrm{A}}$ receptors exhibit two distinct and separable agonist affinities. J. Physiol. 581, 1001-1018 (2007).

53. Pierce, S. R., Senneff, T. C., Germann, A. L. \& Akk, G. Steady-state activation of the high-affinity isoform of the $\alpha 4 \beta 2 \delta \mathrm{GABA}_{\mathrm{A}}$ receptor. Sci. Rep. 9, 15997 (2019).

54. Connolly, C. N., Wooltorton, J. R., Smart, T. G. \& Moss, S. J. Subcellular localization of $\gamma$-aminobutyric acid type A receptors is determined by receptor $\beta$ subunits. Proc. Natl Acad. Sci. USA 93, 9899-9904 (1996).

55. Sieghart, W., Ramerstorfer, J., Sarto-Jackson, I., Varagic, Z. \& Ernst, M. A novel $\mathrm{GABA}_{\mathrm{A}}$ receptor pharmacology: drugs interacting with the $\alpha^{+} \beta^{-}$ interface. Br. J. Pharmacol. 166, 476-485 (2012).

56. Varagic, Z. et al. Identification of novel positive allosteric modulators and null modulators at the $\mathrm{GABA}_{\mathrm{A}}$ receptor $\alpha^{+} \beta^{-}$interface. Br. J. Pharmacol. 169, 371-383 (2013).

57. Khatri, A. \& Weiss, D. S. The role of Loop F in the activation of the GABA receptor. J. Physiol. 588, 59-66 (2010).

58. Palvolgyi, A. et al. Loop $\mathrm{F}$ of the $\mathrm{GABA}_{\mathrm{A}}$ receptor alpha subunit governs GABA potency. Neuropharmacology 128, 408-415 (2018).

59. Zhang, J., Xue, F. \& Chang, Y. Agonist- and antagonist-induced conformational changes of loop $F$ and their contributions to the $\rho 1$ GABA receptor function. J. Physiol. 587, 139-153 (2009).

60. Williams, C. A., Bell, S. V. \& Jenkins, A. A residue in loop 9 of the $\beta 2$-subunit stabilizes the closed state of the $\mathrm{GABA}_{\mathrm{A}}$ receptor. J. Biol. Chem. 285, 7281-7287 (2010).

61. Anstee, Q. M. et al. Mutations in the GABRB1 gene promote alcohol consumption through increased tonic inhibition. Nat. Commun. 4, 2816 (2013).

62. Mozrzymas, J. W., Barberis, A., Mercik, K. \& Zarnowska, E. D. Binding sites, singly bound states, and conformation coupling shape GABA-evoked currents. J. Neurophysiol. 89, 871-883 (2003).
63. Nayak, T. K., Vij, R., Bruhova, I., Shandilya, J. \& Auerbach, A. Efficiency measures the conversion of agonist binding energy into receptor conformational change. J. Gen. Physiol. 151, 465-477 (2019).

64. Bright, D. P., Aller, M. I. \& Brickley, S. G. Synaptic release generates a tonic $\mathrm{GABA}_{\mathrm{A}}$ receptor-mediated conductance that modulates burst precision in thalamic relay neurons. J. Neurosci. 27, 2560-2569 (2007).

65. Santhakumar, V., Jones, R. T. \& Mody, I. Developmental regulation and neuroprotective effects of striatal tonic $\mathrm{GABA}_{\mathrm{A}}$ currents. Neuroscience 167, 644-655 (2010)

66. Janssen, M., Yasuda, R. \& Vicini, S. GABA $A_{A}$ receptor $\beta 3$ subunit expression regulates tonic current in developing striatopallidal medium spiny neurons. Front. Cell. Neurosci. 5, https://doi.org/10.3389/fncel.2011.00015 (2011).

67. Adams, J. M., Thomas, P. \& Smart, T. G. Modulation of neurosteroid potentiation by protein kinases at synaptic- and extrasynaptic-type $\mathrm{GABA}_{\mathrm{A}}$ receptors. Neuropharmacology 88, 63-73 (2015).

68. Connelly, W. M. et al. $\mathrm{GABA}_{\mathrm{B}}$ receptors regulate extrasynaptic $\mathrm{GABA}_{\mathrm{A}}$ receptors. J. Neurosci. 33, 3780-3785 (2013).

69. Homanics, G. E. et al. Mice devoid of $\gamma$-aminobutyrate type A receptor $\beta 3$ subunit have epilepsy, cleft palate, and hypersensitive behavior. Proc. Natl Acad. Sci. USA 94, 4143-4148 (1997).

70. Møller, R. S. et al. Mutations in GABRB3: from febrile seizures to epileptic encephalopathies. Neurology 88, 483-492 (2017).

71. Mortensen, M. \& Smart, T. G. Single-channel recording of ligand-gated ion channels. Nat. Protoc. 2, 2826-2841 (2007).

72. Krivov, G. G., Shapovalov, M. V. \& Dunbrack, R. L. Jr. Improved prediction of protein side-chain conformations with SCWRL4. Proteins 77, 778-795 (2009).

\section{Acknowledgements}

This work was supported by the UK Medical Research Council (MRC, T.G.S.). C.S. was in receipt of an MRC postgraduate studentship.

\section{Author contributions}

C.S. performed the majority of the experiments and analysed data, R.P. performed some electrophysiological experiments, M.M. created the GABA $A_{A}$ homology model, D.B. helped design and direct the study, T.G.S. designed and directed the study, obtained funding and analysed data. All authors participated in the writing of the paper and the presentation of data.

\section{Competing interests}

The authors declare no competing interests.

\section{Additional information}

Supplementary information The online version contains supplementary material available at https://doi.org/10.1038/s41467-021-25633-0.

Correspondence and requests for materials should be addressed to Trevor G. Smart.

Peer review information Nature Communications thanks Rooma Desai, Margot Ernst and Jin Zhe for their contribution to the peer review of this work.

Reprints and permission information is available at http://www.nature.com/reprints

Publisher's note Springer Nature remains neutral with regard to jurisdictional claims in published maps and institutional affiliations.

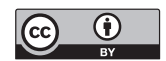

Open Access This article is licensed under a Creative Commons Attribution 4.0 International License, which permits use, sharing, adaptation, distribution and reproduction in any medium or format, as long as you give appropriate credit to the original author(s) and the source, provide a link to the Creative Commons license, and indicate if changes were made. The images or other third party material in this article are included in the article's Creative Commons license, unless indicated otherwise in a credit line to the material. If material is not included in the article's Creative Commons license and your intended use is not permitted by statutory regulation or exceeds the permitted use, you will need to obtain permission directly from the copyright holder. To view a copy of this license, visit http://creativecommons.org/ licenses/by/4.0/.

(C) The Author(s) 2021 